\title{
A pilot study on the usefulness of peripheral blood flow cytometry for the diagnosis of lower risk myelodysplastic syndromes: the "MDS thermometer"
}

Ana Aires ${ }^{1,3}$, Maria dos Anjos Teixeira ${ }^{1,4,5}$, Catarina Lau ${ }^{1,4,5}$, Cláudia Moreira ${ }^{1}$, Ana Spínola ${ }^{1}$, Alexandra Mota ${ }^{1,3}$, Inês Freitas ${ }^{2,4}$, Jorge Coutinho ${ }^{1}$ and Margarida Lima ${ }^{1,3,4,5^{*}}$ (i)

\begin{abstract}
Background: Immunophenotypic analysis of the bone marrow (BM) cells has proven to be helpful in the diagnosis of Myelodysplastic Syndromes (MDS). However, the usefulness of flow cytometry (FCM) for the detection of myelodysplasia in the peripheral blood (PB) still needs to be investigated. The aim of this pilot study was to evaluate the value of FCM-based PB neutrophil and monocyte immunophenotyping for the diagnosis of lower risk MDS (LR-MDS).

Methods: We evaluated by 8-color FCM the expression of multiple cell surface molecules (CD10, CD11b, CD11C, CD13, CD14, CD15, CD16, CD34, CD45, CD56, CD64 and HLA-DR) in PB neutrophils and monocytes from a series of 14 adult LR-MDS patients versus 14 normal individuals.

Results: Peripheral blood neutrophils from patients with LR-MDS frequently had low forward scatter (FSC) and side scatter (SSC) values and low levels of CD11b, CD11C, CD10, CD16, CD13 and CD45 expression, in that order, as compared to normal neutrophils. In addition, patients with LR-MDS commonly display a higher fraction of $\mathrm{CD} 14^{+} \mathrm{CD} 56^{+}$and a lower fraction of $\mathrm{CD} 14^{+} \mathrm{CD} 16^{+}$monocytes in the PB. Based on these results, we proposed an immunophenotyping score based on which PB samples from patients with LR-MDS could be distinguished from normal PB samples with a sensitivity $93 \%$ and a specificity of 100\%. In addition, we used this score to construct the MDS Thermometer, a screening tool for detection and monitoring of MDS in the PB in clinical practice.

Conclusions: Peripheral blood neutrophil and monocyte immunophenotyping provide useful information for the diagnosis of LR-MDS, as a complement to cytomorphology. If validated by subsequent studies in larger series of MDS patients and extended to non-MDS patients with cytopenias, our findings may improve the diagnostic assessment and avoid invasive procedures in selected groups of MDS patients.
\end{abstract}

Keywords: Myelodysplastic syndromes, Lower risk MDS, Peripheral blood, Flow cytometry

\footnotetext{
* Correspondence: mmc.lima@clix.pt

'Department of Hematology, Hospital de Santo António (HSA), Centro

Hospitalar do Porto (CHP), Porto, Portugal

${ }^{3}$ Instituto de Ciências Biomédicas Abel Salazar, Universidade do Porto (ICBAS/

UP), Porto, Portugal

Full list of author information is available at the end of the article
} 


\section{Background}

Myelodysplastic Syndromes (MDS) are a group of myeloid neoplasms characterized by inefficient hematopoiesis, peripheral blood (PB) cytopenias and high risk of leukemic progression [1-3]. According to World Health Organization (WHO) classification, lastly updated in 2016, the diagnosis is essentially based on morphological and cytogenetic abnormalities, such as the presence of cytopenias, blasts in the $\mathrm{PB}$ and/or bone marrow (BM), and dysplasia in one or more hematopoietic cell lineages $[4,5]$. Although PB cytomorphological findings provide information to suspect of MDS, only BM studies are presently accepted to confirm the diagnosis $[4,5]$.

Five major MDS subtypes are currently recognized (WHO, 2016): MDS with single lineage dysplasia (MDSSLD), MDS with multilineage dysplasia (MDS-MLD), MDS with ring sideroblasts (MDS-RS), MDS with isolated deletion of chromosome $5 q$ [MDS-del(5q)], MDS with excess of blasts (MDS-EB), and MDS, unclassifiable (MDS-U) [5]. The International Prognostic Scoring System (IPSS), has been used to estimate risk for progression to acute myeloid leukemia (AML) or death from cytopenia-related complications. [6]. Patients categorized as low or intermediate-1 risk using the IPSS are usually referred to as "lower-risk" MDS (LR-MDS), whereas those classified as intermediate- 2 or high risk are usually termed "higher-risk" MDS (LR-MDS). In its revised version, the IPSS incorporated new BM blast classes and cytogenetic abnormalities, and included both number and severity of cytopenias, thereby defining five (very low, low, intermediate, high and very high) risk categories, from which the first three correspond to LR-MDS [7]. In general, these include MDS-SLD, MDS-MLD, MDS-RS and MDS-del(5q).

Most of the LR-MDS patients, who account for around $60 \%$ of newly diagnosed MDS cases, remain simply on supportive care, being dependent on red blood cell (RBC) and/or platelet transfusions, and/or receiving hematopoietic growth factors; about $1 / 3$ of the patients only require monitoring ("wait and see") [8]. HR-MDS patients may benefit from intensive treatments, although most of them are not eligible due to increased age and/ or comorbidities, thereby being selected for lowintensity treatment regimens [8].

Flow cytometry (FCM) is a highly sensitive technique for evaluation of the hematopoietic cells. It has been used with increasing frequency to study the BM from patients with MDS, being considered a promising tool to improve MDS diagnosis, especially in cases of minimal dysplasia, absence of cytogenetic abnormalities, and BM hypocellularity or fibrosis [9-16]. Its value in the diagnosis of Chronic Myelomonocytic Leukemia (CMML) and other Myelodysplastic/myeloproliferative neoplasms (MDS/MPN) has also been documented [17-20].
Flow cytometry has an increasing importance in MDS diagnosis and subtyping, and in predicting the clinical outcome [15, 21]. However, a systematic histological and immuno-histochemical examination of the BM is still required for the final diagnosis and classification of MDS [22].

Several immunophenotypic abnormalities have been reported by FCM in the BM from MDS patients. Some examples are increased numbers of $\mathrm{CD}^{+} 4^{+}$precursors, abnormal expression of cell surface molecules on myeloblasts, maturing granulocytic and monocytic cells, or erythroid precursors, and lineage infidelity [13]. For instance, phenotypic abnormalities of $\mathrm{CD} 4^{+}$cells and their compartments have been reported in MDS, with LR-MDS patients typically having an expansion of myeloid $\mathrm{CD}_{34}{ }^{+}$cells at the expense of lymphoid B-cell precursors, while expansion of immature $\mathrm{CD}^{+}{ }^{+}$cells occurs in HR-MDS [11, 23]. Aberrant antigen expression (e.g., CD5, CD7 and CD56), and over or under expression of other cell surface markers (e.g. CD13, CD34, CD45, CD117 and HLA-DR) on $\mathrm{CD}^{+} 4^{+}$myeloblasts have also been reported $[12,24]$.

Asynchronous shift to the left in maturing granulocytes is also frequent in the BM from patients with MDS, with neutrophil-precursors and maturing neutrophils having decreased size and granularity, and, consequently, a lower light scatter. Abnormal/Asynchronous expression of CD11b, CD13, CD15 and CD16 molecules has also been described, reflecting an anomalous neutrophil maturation [9, 10, 12]. Likewise, BM monocytes from MDS patients frequently have abnormal maturation patterns, as evaluated by the expression of CD14, CD34, CD36, CD64, and HLA-DR. Erythroid dysplasia has also been documented by FCM, by studying a set of molecules that are expressed differently throughout the maturation of $\mathrm{RBC}$ in the $\mathrm{BM}$, such as CD35, CD36, CD44, CD45, CD71, CD105, CD117 and CD235a [9, 12, 25, 26].

Even though the collection of a PB sample is much simpler and much less invasive than a BM aspirate and/or biopsy, nearly all FCM studies in MDS patients have been performed in BM samples; the immunophenotypic alterations in $\mathrm{PB}$ cells have been much less explored [27-31].

Taking in consideration the accessibility of PB samples, it would be useful to establish FCM criteria for the diagnosis of myelodysplasia in the $\mathrm{PB}$, especially in patients with LR-MDS. Therefore, the purpose of this study was to search the presence of abnormal and/or aberrant antigen expression in circulating neutrophils and monocytes from these patients. Based on the results obtained, a straightforward FCM-based scoring system is proposed, which allows to distinguish $\mathrm{PB}$ samples of patients with LR-MDS from normal PB samples with a high sensitivity and specificity. Using this scoring schema we, conceived 
the MDS Thermometer, a simple screening tool for detection and monitoring of MDS in the $\mathrm{PB}$ in clinical practice.

\section{Methods}

\section{Study population and design}

This study included 14 patients with LR-MDS, 8 males and 6 females, with a median age of 76 years, ranging from 66 to 88 years, that had been followed in the Hematology Department of Centro Hospitalar do Porto, Porto, Portugal, and that had at least one appointment at the hospital from September 2015 to November 2015.

An equal number of healthy controls (blood donors) were studied in parallel, 8 males and 6 females, with a median age of 55 years, ranging 19 to 63 years. First time donors, and donors with a history of infection in the previous 3 months and/or who have had neoplasms were excluded.

Clinical and laboratory data were retrospectively collected from the hospital records. Patients were considered to have anemia, neutropenia and thrombocytopenia if hemoglobin $(\mathrm{Hg})<12.5 \mathrm{~g} / \mathrm{dL}$, neutrophils $<2.000 \times 10^{6} / \mathrm{L}$ and platelets $<150 \times 10^{9} / \mathrm{L}$, respectively.

The diagnosis and classification of MDS were established according to the WHO criteria, revised in 2016 $[4,5]$, after excluding other conditions that could potentially contribute to BM dysplasia and/or cytopenias. Only the following LR-MDS categories were included: MDS-SLD, MDS-MLD, MDS-RS and MDS-del(5q).

In order to avoid artefactual effects on neutrophil and monocyte immunophenotypes, patients who were being treated with granulocyte (G-CSF) or granulocytemacrophage (GM-CSF) colony stimulating factors (CSF) at the time of the study or in the preceding 3 months were excluded, as did patients submitted to cytoreductive therapy, lenalidomide, hypomethylating and/or immunosuppressive treatments, and patients with concomitant infections or other neoplastic diseases. Previous or concomitant treatments with erythropoietin (EPO) and thrombopoietin receptor agonists were not exclusion criteria, neither did iron chelating therapies, vitamins or other nutrients.

The IPSS and the revised IPSS (IPSS-R) were calculated for all patients with MDS as previously described [6, 7]. Levels of $\mathrm{Hg}<10.0 \mathrm{~g} / \mathrm{dL}$, neutrophils $<1800 \times 10^{6} / \mathrm{L}$ and platelets $<100 \times 10^{9} / \mathrm{L}$ were considered for risk stratification. The IPSS criteria were used to derive the karyotypebased risk classification [6].

Transfusion-related variables included the cumulative transfusion burden (total number of $\mathrm{RBC}$ units) and transfusion intensity (median number of RBC units/ month). Transfusion-dependency was defined according to the WHO classification-based Prognostic Scoring System criteria [2].
Given the fact that elevated lactate dehydrogenase (LDH) has been associated with decreased overall survival [32], serum LDH levels were also evaluated. Moreover, as most patients with MDS were RBC transfusion-dependent [14, 33], and iron overload has been associated with worse prognosis in patients with LR-MDS [34], the serum ferritin levels were measured.

Bone marrow aspirate samples were used to prepare BM smears. These were stained with Leishman's stain, and cell morphology was analyzed by conventional light microscopy. In each case, a Perls' Prussian blue stain was performed. Other special stains were used whenever considered helpful. The acceptable quality of samples was defined according to the guidelines of the International Council for Standardization in Hematology [35]. Erythroid and granulocytic dysplasia were defined by the presence of $\geq 10 \% \mathrm{BM}$ cells of the respective lineage with morphological alterations; presence of $\geq 15 \%$ ringed sideroblasts was also considered a diagnostic criteria for erythroid dysplasia. Megakaryocytic dysplasia was recognized by the presence of morphological abnormalities. Morphological features used for the definition of myeloblasts were those proposed by the International Working Group on Morphology of MDS [35], and the blast cell percentage was determined using the overall number of BM nucleated cells as denominator.

Bone marrow biopsy specimens were fixed in neutralbuffered formalin or Bouin's fixative solution, decalcified, and embedded in paraffin-wax. Standard routine stains included hematoxylin \& eosin and/or Giemsa, and Gömöri's silver stain for the evaluation of BM fibrosis [36]. Immunohistochemistry was done in specific cases. The BM cellularity was estimated based on the ageadapted normal values [36], and dysmyelopoiesis was evaluated as previously described [37, 38].

Cytogenetics studies were performed in BM aspirates, either by conventional cytogenetics and/or fluorescence in situ hybridization (FISH). Conventional cytogenetics was performed on direct and 24- to 48-h unstimulated BM cultures, analyzed following trypsin Giemsa banding; 20 metaphases were evaluated. In FISH studies, VYSIS DNA FISH probes (Abbott Molecular Inc., IL, USA) were used to detect numeric and structural abnormalities on chromosomes 5, 7 and 20, and numeric abnormalities on chromosomes 8 and X. Two hundred interphase nuclei were counted. Cytogenetic classification was performed by grouping patients according to Schanz et al. [39].

\section{Flow cytometry studies}

Peripheral blood samples were collected into ethylenediamine-tetra-acetic acid tripotassium salt containing tubes and processed within $24 \mathrm{~h}$ after collection. 
Cell immunophenotyping was performed by 8-color FCM using fluorochrome conjugated monoclonal antibodies (mAbs) with different specificities (Table 1). These mAbs were combined in two different tubes, conceived to quantify immature $\mathrm{CD}_{34}{ }^{+}$cell in the PB and to evaluate cell surface antigen expression in circulating neutrophils (mostly tube 1) and monocytes (mostly tube 2) (Table 2). A normal PB sample was run in parallel with each patient $\mathrm{PB}$ sample.

Cell staining was done using a whole blood stain-lyseand-then-wash method, and the BD FACS ${ }^{\mathrm{mm}}$ Lysing Solution, according to the instructions of the manufacturer.

Sample acquisition was performed in a BD FACSCanto II $^{\mathrm{Tu}}$ flow cytometer. Forward scatter (FSC) and side scatter (SSC) were captured on a linear scale, and SSC was represented with a mathematical transformation (Exp-SSC-Low). For fluorescence parameters, a logarithmic amplification was used, with logical transformation. At least 200,000 cell events per tube were recorded and stored as flow cytometry standard (.fcs) 3.0 files.

Flow cytometer set-up and calibration was performed accordingly to the Euroflow consortium Standard Operating Procedures [40], available in [41]. Daily control was monitored by plotting fluorescence intensity values in Levy Jennings charts. External quality assessment/proficiency testing was performed by participating in the Euroflow Quality Assurance program [42].

Flow cytometry data analysis was done using the Infinicyt $^{\text {tw }}$ software (Cytognos, Salamanca, Spain). Neutrophils, monocytes and blast cells were identified and classified according to their SSC and FSC characteristics and antigen expression profiles, as described in Fig. 1.

Table 1 Specificities, clones, isotypes, fluorochromes and manufacturers of the monoclonal antibodies used in this study

\begin{tabular}{lllll}
\hline Antigen & Clone & Isotype & Fluorochrome & Manufacturer \\
\hline CD10 & ALB1 & $\operatorname{lgG} 2 \mathrm{a}$ & PE-Cy7 & BC-IOT \\
CD11b & D12 & $\operatorname{lgG} 2 \mathrm{a}$ & APC & BDB \\
CD11c & S-HCL-3 & $\operatorname{lgG} 2 \mathrm{~b}$ & APC & BDB \\
CD13 & L138 & $\operatorname{lgG1}$ & PE & BDB \\
CD14 & HCD14 & $\operatorname{lgG1}$ & APC-H7 & BL \\
CD15 & MMA & $\operatorname{lgM}$ & FITC & BDB \\
CD16 & $3 G 8$ & $\operatorname{lgG1}$ & V450 & BDH \\
CD34 & $8 G 12$ & $\operatorname{lgG1}$ & PerCP-Cy5.5 & BDB \\
CD45 & J.33 & $\operatorname{lgG1}$ & KO & BC-IOT \\
CD56 & N901-HLDA6 & $\operatorname{lgG1}$ & PE-Cy7 & BC-IOT \\
CD64 & 22 & $\operatorname{lgG1}$ & PE & BC-IOT \\
HLA-DR & L243 & $\operatorname{lgG2a}$ & FITC & BDB \\
\hline
\end{tabular}

Abbreviations: APC allophycocyanin, Cy5.5 Cyanine 5.5, Cy7 Cyanine 7, FITC Fluorescein, isothiocyanate, KO Khrome Orange, $P E$ Phycoerythrin, $\operatorname{Per} C P$ Peridinin chlorophyll protein, V450 Violet 450, BC Beckman Coulter, $B D B$ Becton Dickinson Bioscience, $B D H$ Becton Dickinson Horizon, $B L$ Biolegend, IOT Immunotech
Monocytes were further subdivided into classical (CD14 thigh $\left.\mathrm{CD} 16^{-}\right)$, intermediate $\left(\mathrm{CD} 14^{\text {+high }} \mathrm{CD} 16^{+}\right)$and proinflammatory $\left(\mathrm{CD} 14^{+ \text {low }} \mathrm{CD} 16^{+}\right)$monocytes. Non-classical $\left(\mathrm{CD} 14^{+} \mathrm{CD} 16^{+}\right.$, intermediate + proinflammatory) monocyte subsets were considered together in succeeding analysis. Neutrophils and monocytes were analyzed for the levels of expression of CD10, CD11b, CD11c, CD13, CD15, CD16, CD56, CD64, and HLA-DR, by recording the median fluorescence intensity (MedFI) for each marker. The relative representation of $\mathrm{CD} 14^{+} \mathrm{CD} 16^{-}$and $\mathrm{CD} 14^{+} \mathrm{CD} 16^{+}$monocyte subsets and the percentage of $\mathrm{CD} 6^{+}$monocytes were also recorded.

The FSC/SSC values and MedFI values obtained in neutrophils and monocytes from patients with LR-MDS were considered abnormal when they were out of the mean value \pm 2 standard deviations (SD) of the same parameter obtained in $\mathrm{PB}$ neutrophils and monocytes from healthy individuals.

\section{Immunophenotypic scores for myelodysplasia Neutrophil scores}

Two different scoring schemas were used for neutrophils. The scoring schema type 1 was based only on the number of abnormally low parameters found in $\mathrm{PB}$ neutrophils (below the mean-2SD of the values found for the same parameter in normal PB neutrophils). The scoring schema type 2 took into account both the number of abnormally low parameters and the severity of each parameter deficiency, as previously described [11,23].

In both cases, values within the mean $\pm 2 \mathrm{SD}$ or above the mean $+2 \mathrm{SD}$ were scored with "0", and in both cases only 8 of the parameters analyzed (FSC, SSC, CD10, CD11b, CD11c, CD13, CD16 and CD45) were considered for scoring. The neutrophil score, ranging from 0 to 8 in both cases, was calculated for each patient by adding up the scores obtained for each of the 8 parameters evaluated. Three groups corresponding to an overall score of " 0 ", 1 and $\geq 2$ were arbitrarily considered equivalent to "no neutrophil dysplasia", "possible neutrophil dysplasia" and "neutrophil dysplasia", respectively. Cases with a neutrophil score $\geq 2$ were subsequently arbitrarily classified as having mild (scores 2 and 3), moderate (scores 4, 5 and 6) and severe (scores 7 and 8) neutrophil dysplasia, respectively.

Neutrophil scoring schema 1 Each abnormally low parameter (below the mean-2SD) was scored with 1 point.

Neutrophil scoring schema 2 Values of $0.25,0.5$ or 1.0 were given when the MedFI value obtained for each of the phenotypic variables evaluated were between the mean-2SD and the mean-3SD, between the mean-3SD and the mean-4 SD, or below the mean-4SD of the 
Table 2 Eight color-combinations of the fluorochrome-conjugated monoclonal antibodies used in this study

\begin{tabular}{lllllllll}
\hline Tubes & FITC & PE & PerCP-Cy5 & PE-Cy7 & APC & APC-H7 & V450 & KO \\
\hline 1 & CD15 & CD13 & CD34 & CD10 & CD11b & CD14 & CD16 & CD45 \\
2 & HLA-DR & CD64 & CD34 & CD56 & CD11c & CD14 & CD16 & CD45
\end{tabular}

Abbreviations: $A P C$ allophycocyanin, Cy5.5 Cyanine 5.5, Cy7 Cyanine 7, FITC Fluorescein, isothiocyanate, KO Khrome Orange, $P E$ Phycoerythrin, PerCP Peridinin chlorophyll protein, $\mathbf{V} 450$ Violet 450

values found for the same parameter in normal PB neutrophils, respectively.

\section{Monocyte scores}

For monocytes, only the percentages of $\mathrm{CD} 14^{+} \mathrm{CD} 56^{+}$ and $\mathrm{CD} 14^{+} \mathrm{CD} 16^{+}$monocytes on total monocytes were used to calculate the FCM monocyte score for myelodysplasia. Aberrant high CD56 expression was defined as a percentage of $\mathrm{CD}_{5} 6^{+}$cells exceeding the mean + $2 \mathrm{SD}$ of the values found in normal PB monocytes. Abnormal low CD16 expression was defined as a percentage of $\mathrm{CD} 14^{+} \mathrm{CD} 16^{+}$monocytes of less than $5 \%$ of total monocytes. Depletion of non-classical monocytes was arbitrarily considered mild, moderate or severe when $\mathrm{CD} 14^{+} \mathrm{CD} 16^{+}$cells accounted for less than $5 \%, 2.5 \%$ and $1.25 \%$ of total monocytes, respectively. The overall monocyte score, ranging from 0 to 2 , was calculated for each patient by adding up the scores obtained for each of the 2 parameters evaluated.

As described for neutrophils, two different scoring schemas were used for monocytes: scoring schema type 1 , based only on the number abnormal parameters found in $\mathrm{PB}$ monocytes, and scoring schema type 2, taking into account both the number of abnormal parameters and the severity of each parameter abnormality. The monocyte score, ranging from 0 to 2 , was calculated for each patient by adding up the scores obtained for each of the 2 parameters evaluated. Three groups corresponding to an overall score of 0,1 and 2, were arbitrarily considered equivalent to "no monocyte dysplasia", "possible monocyte dysplasia" and "monocyte dysplasia", respectively.

Monocyte scoring schema 1 Each abnormal parameter (percentage of $\mathrm{CD}^{2} 6^{+}$cells exceeding the mean $+2 \mathrm{SD}$

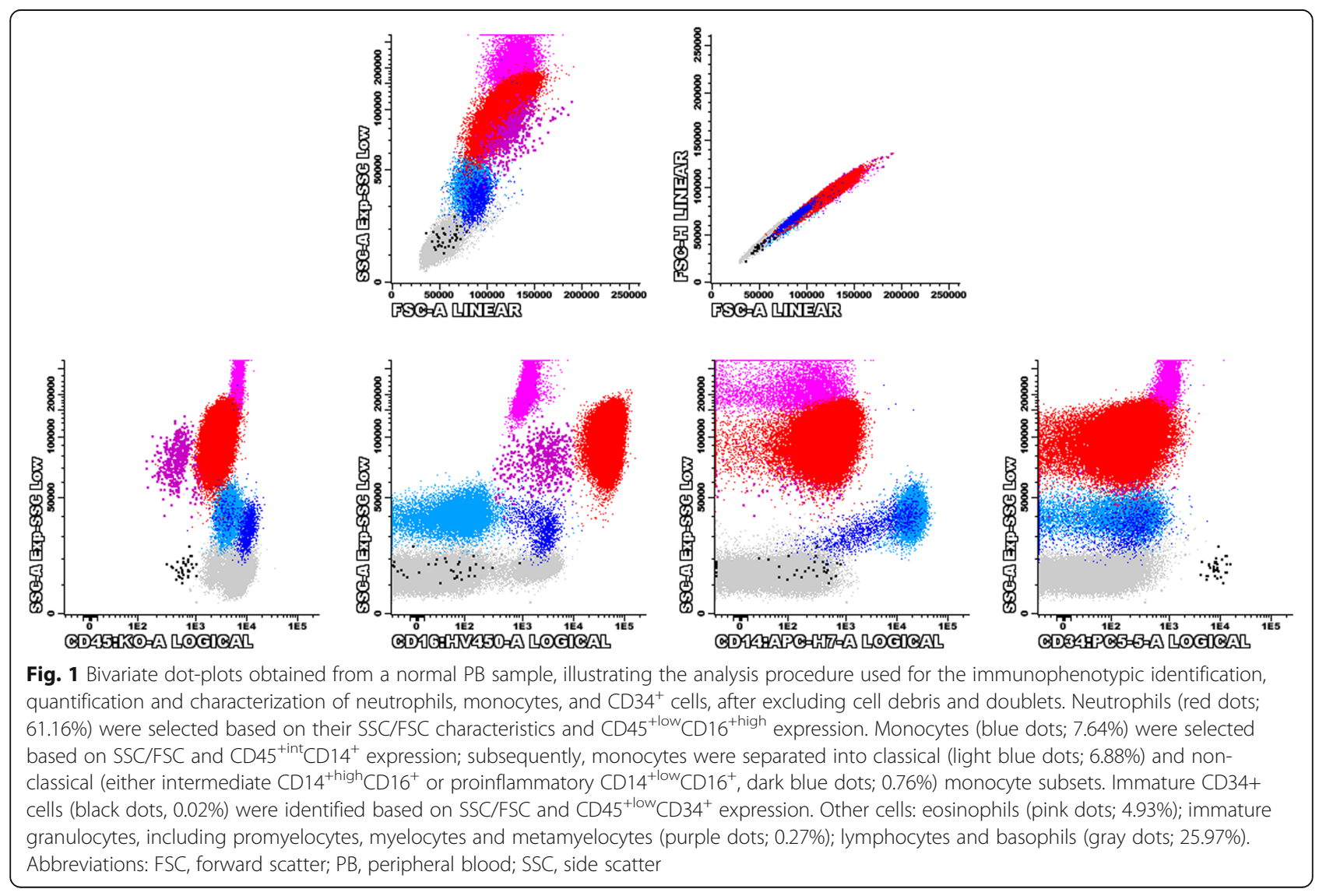


and percentage of $\mathrm{CD} 16^{+}$cells $\left.<5 \%\right)$ was scored with 1 point.

Monocyte scoring system 2 Values of $0.25,0.5$ or 1 were given when the \% of $\mathrm{CD}^{+} 6^{+}$monocytes were between the mean $+2 \mathrm{SD}$ and the mean $+3 \mathrm{SD}$, between the mean $+3 \mathrm{SD}$ and the mean $+4 \mathrm{SD}$, or above the mean + $4 \mathrm{SD}$ of the values found for the same parameter among normal PB monocytes, respectively. Values of $0.25,0.5$ or 1 were assumed when the percentages of $\mathrm{CD} 16^{+}$ monocytes were between the 2.5 and $5.0 \%$, between $1.25 \%$ and $2.5 \%$ and below $1.25 \%$, respectively.

\section{Myeloid immunophenotypic scores}

Two myeloid immunophenotypic MDS scores, type 1 and type 2 , both ranging from 0 to 10 , were obtained for each patient by adding up the correspondent neutrophil and monocytic MDS scores. Three groups corresponding to overall scores of "0", 1 and $\geq 2$ were arbitrarily considered equivalent to "no myelodysplasia", "possible myelodysplasia" and "myelodysplasia", respectively. Cases with a myeloid score $\geq 2$ were subsequently classified as having mild (scores 2 to 4 ), moderate (scores 5 to 7 ) and severe (scores 8 to 10) myelodysplasia, respectively.

\section{MDS thermometer}

The MDS Thermometer was conceived as a screening tool for detection and monitoring of MDS in clinical practice. It consists in a visual analogue scale rated from 0 to 10 points (myeloid thermometer) with two domains (neutrophil thermometer, rated from 0 to 8 , and monocyte thermometer, rated from 0 to 2) based on the immunophenotypic scores defined above. For simplicity, only the neutrophil and monocyte scoring schemas type 1 were used to construct the MDS Thermometer presented in this paper. The concept was based on the Emotion Thermometers Tool, created by Alex J Mitchell [43, 44].

\section{Statistical analysis}

Results were expressed as absolute and relative frequencies, or as mean, median, SD, minimum and maximum values. Results obtained in PB samples of MDS patients were compared with those obtained in control PB samples. The non-parametric Mann-Whitney $U$ test was used to compare the MedFI observed for each marker in PB neutrophils and monocytes from MDS patients and controls, as well as to compare blood cell counts at the time of the study with those at diagnosis. $P$ values $<0.05$ were considered statistically significant. All statistical analyses were performed using the SOFA Statistics version 1.4.5 (Paton-Simpson \& Associates Ltd., Auckland, New Zealand).

\section{Results}

\section{Study population}

Table 3 summarizes the demographic, clinical and laboratory data of the study population. Detailed data can be found in Supplementary Material (Additional file 1: Table S1).

According to the WHO criteria, 6 patients were classified as MDS-RS, 4 patients had MDS-SLD, 3 patients had MDS-MLD, and 1 patient was classified as MDSisolated 5q- (Table 3).

Using the IPSS, all patients were categorized as LRMDS: 8 patients had low IPSS risk and 6 patients had intermediate 1 IPSS risk (Table 3).

Cytogenetic based stratification revealed good or intermediate risk in 9 cases and 1 case, respectively (Table 3 ).

Table 3 MDS categories and risk stratification of the patients included in this study

Diagnosis (WHO 2016) ${ }^{\mathrm{a}}$

\begin{tabular}{|c|c|}
\hline MDS-RS & $6 / 14(43 \%)$ \\
\hline MDS-SLD & 4/14 (29\%) \\
\hline MDS-MLD & $3 / 14(21 \%)$ \\
\hline MDS-del(5q) & $1 / 14(7 \%)$ \\
\hline \multicolumn{2}{|c|}{ ternational Prognostic Scoring System (IPSS) } \\
\hline IPSS score & $0.3 \pm 0.4 ; 0(0-1.0)$ \\
\hline Score $=0.0$ & 8/14 (57\%) \\
\hline Score $=0.5$ & $3 / 14(21 \%)$ \\
\hline Score $=1.0$ & $3 / 14(21 \%)$ \\
\hline Score $>1.0$ & $0 / 14(0 \%)$ \\
\hline \multicolumn{2}{|l|}{ IPSS risk groups } \\
\hline Low risk & 8/14 (57\%) \\
\hline Intermediate risk 1 & $6 / 14(43 \%)$ \\
\hline Intermediate risk 2 & $0 / 14(0 \%)$ \\
\hline High risk & $0 / 14(0 \%)$ \\
\hline \multicolumn{2}{|c|}{ ytogenetic based risk classification ${ }^{b}$} \\
\hline Very good & $0 / 10(0 \%)$ \\
\hline Good & 9/10 (90\%) \\
\hline Intermediate & $1 / 10(10 \%)$ \\
\hline Poor & 0/10 (0\%) \\
\hline Very poor & $0 / 10(0 \%)$ \\
\hline
\end{tabular}

Abbreviations: IPSS International Prognostic Scoring System, MDS myelodysplastic syndromes, MDS-del(5q) MDS with isolated deletion of chromosome 5q, MDS-MLD MDS with multilineage dysplasia, MDS-RS MDS with ring sideroblasts, MDS-SLD MDS with single lineage dysplasia, WHO World Health Organization

Results are expressed as absolute and (relative) frequencies

a Patients with MDS unclassifiable or with $\geq 20 \%$ blast in the BM were omitted, as did patients with MDS with excess of blasts, and patients diagnosed with Myelodysplastic/myeloproliferative neoplasms

${ }^{b}$ Cytogenetic scoring: Very good: $-Y$, del(11q); Good: normal, del(5q), del(12p), del(20q), double including del(5q); Intermediate: del(7q), $+8,+19$, i(17q), any other single or double independent clones; Poor: -7 , inv.(3)/t(3q), del3q, double including $-7 / \operatorname{del}(7 q)$, complex (3 abnormalities); Very poor: complex (> 3 abnormalities) 
Overall, metaphase cytogenetics and/or interphase FISH testing for $-5 / 5 q_{-},-7 / 7 q_{-},+8$, and $20 q_{-}$, identified in cytogenetic aberrancies in only 2 out 10 cases $(20 \%)$, corresponding to isolated del(5q) (1 patient) and isolated monosomy 8 (1 case); cytogenetic data were unavailable in 4 cases (Additional file 1: Table S1).

The median time from the diagnosis was 7.6 years, ranging from 0.5 to 12.6 years.

At diagnosis, all the MDS patients had anemia, but only 5 (36\%) had neutropenia and only $4(29 \%)$ had thrombocytopenia (Additional file 1: Table S1). The median values of the $\mathrm{Hg}$ levels, and neutrophil and platelet counts were of $9.1 \mathrm{~g} / \mathrm{dl}, 2567 \times 10^{6} / \mathrm{L}$, and $200 \times 10^{9} / \mathrm{L}$ ranging from 7.2 to $11.9,575$ to 7025 and 61 to 591 , respectively. Abnormal RBC morphology in the PB smears were present in all cases, whereas abnormal neutrophil and/or platelet morphological features were observed in 4 patients (29\%) each. At the time of the study, the Hg levels were significantly lower than those observed at the diagnosis $(p=$ 0.006), despite of RBC transfusions; no statistically significant differences were found for the neutrophil and platelet counts, neither for the percentage of blasts in the PB $(p>$ $0.05)$. In addition, although a higher fraction of patients had neutropenia and/or thrombocytopenia, as compared to that observed at diagnosis, differences were also not statistically significant $(\mathrm{p}>0.05)$ (Additional file 1: Table S1 footnote).

Most patients had received RBC transfusions, and most of them had been treated with hematopoietic growth factors at some point during the course of the disease (Additional file 1: Table S1). Concerning blood transfusions, 13 patients $(93 \%)$ had received at least one RBC unit, and eleven (79\%) had been regularly transfused (transfusion-dependent). The median number of $\mathrm{RBC}$ units received per transfused patient was of 57 , ranging from 15 to 462, and a median number of RBC transfused per patient/month was of 1.4, ranging from 0.3 to 4.0 (Additional file 1: Table S1). The mean ferritin serum levels were of $1854 \pm 1126 \mathrm{ng} / \mathrm{ml}$, with $93 \%$ of the patients showing increased serum ferritin values, compatible with iron overload. None of the patients was receiving iron-chelating therapies. In addition, none was medicated with myeloid growth factors (exclusion criteria), although 5 patients had been treated with G-CSF in the past. Only 2 patients were being treated with EPO at the time of the study, although most of them had previously received EPO. No patients had ever received GM-CSF or thrombopoietin receptor agonists. Increased serum LDH levels were seen in only 3 cases (23\%), at the time of the study (Additional file 1: Table S1).

\section{Flow cytometry studies}

\section{Peripheral blood neutrophils}

Neutrophils from patients with LR-MDS had lower FSC and SSC values as compared with controls $(p=0.008$ and $p<0.001$, respectively) (Figs. 2 and 3 , and Additional file 2: Table S2).

In addition, neutrophils from patients with LR-MDS had significantly decreased expression of CD10 $(p<$ $0.001)$, CD11b $(p<0.001)$, CD11c $(p<0.001), \mathrm{CD} 13$ ( $p=$ $0.022)$ and $\mathrm{CD} 16(p=0.002)$ when compared to normal individuals. No statistically significant differences were observed for CD15 and CD45 expression $(p>0.05)$, although both markers had a slight reduction in fluorescence intensity in patients, as compared to controls.

When analyzed individually, neutrophils from most LR-MDS patients had abnormally low FSC and/or SSC ( $71 \%$ and $57 \%$ of cases, respectively) (Table 4 ). Among the cell surface molecules evaluated, CD11b, CD11c, CD10, CD16, CD13 and CD45 were the most frequently affected, in that order; the percentage of cases showing reduced levels of expression of these molecules were of $71 \%, 71 \%, 64 \%, 43 \%, 29 \%$ and $14 \%$, respectively (Table 4 ). Overall, 13 patients (93\%) had abnormally low expression of 2 or more (out of 9) molecules on neutrophils, with 7 patients $(50 \%)$ having abnormally low expression of 5 or more parameters. In addition, 4 cases had abnormally high expression of CD10, CD11b, CD13 or CD45 on circulating neutrophils (1 case each).

In contrast, abnormal levels of cell surface molecules were found in only 4 controls, and the phenotypic abnormalities were restricted to one parameter in all cases (abnormally high CD11b levels: $n=1$; abnormally high CD15 levels: $\mathrm{n}=1$; abnormally low CD15 levels: $\mathrm{n}=1$; abnormally low CD45 levels: $\mathrm{n}=1$ ).

The only patient with a normal neutrophil immunophenotype was a 75 year-old female classified as having MDS-SLD, who had mild macrocytic anemia ( $\mathrm{Hg} 9.0 \mathrm{~g} / \mathrm{dL}$, MCV $104.1 \mathrm{fL}$ ) and mild thrombocytopenia (platelet count of $100 \times 10^{6} / \mathrm{L}$ ). The BM was hypocellular, with $5.3 \%$ blast cells, increased myeloid/erythroid ratio (3.9) and mild dyserythropoiesis, with normal myeloid and megakaryocytic lineages. BM cytogenetics have revealed a 46,XX karyotype with 3 metaphases with non-clonal aneuploidies. The time from the diagnosis was of 31 months, the patient had been occasionally transfused (total of 3 RBC units), and the cytopenias have remained stable over time.

When the healthy controls were separated in two groups according to age ( $<55$ years old, $n=7$ versus $\geq$ 55 years old, $n=7$ ), we did not observe statistically significant differences for any of the parameters analyzed on neutrophils; also, no differences were found between males and females ( $p>0.05$ in all cases).

\section{Peripheral blood monocytes}

In general, monocytes from patients with LR-MDS had light scatter properties similar to the monocytes from normal individuals ( $p>0.05$ ) (Fig. 4 and Additional file 3: 

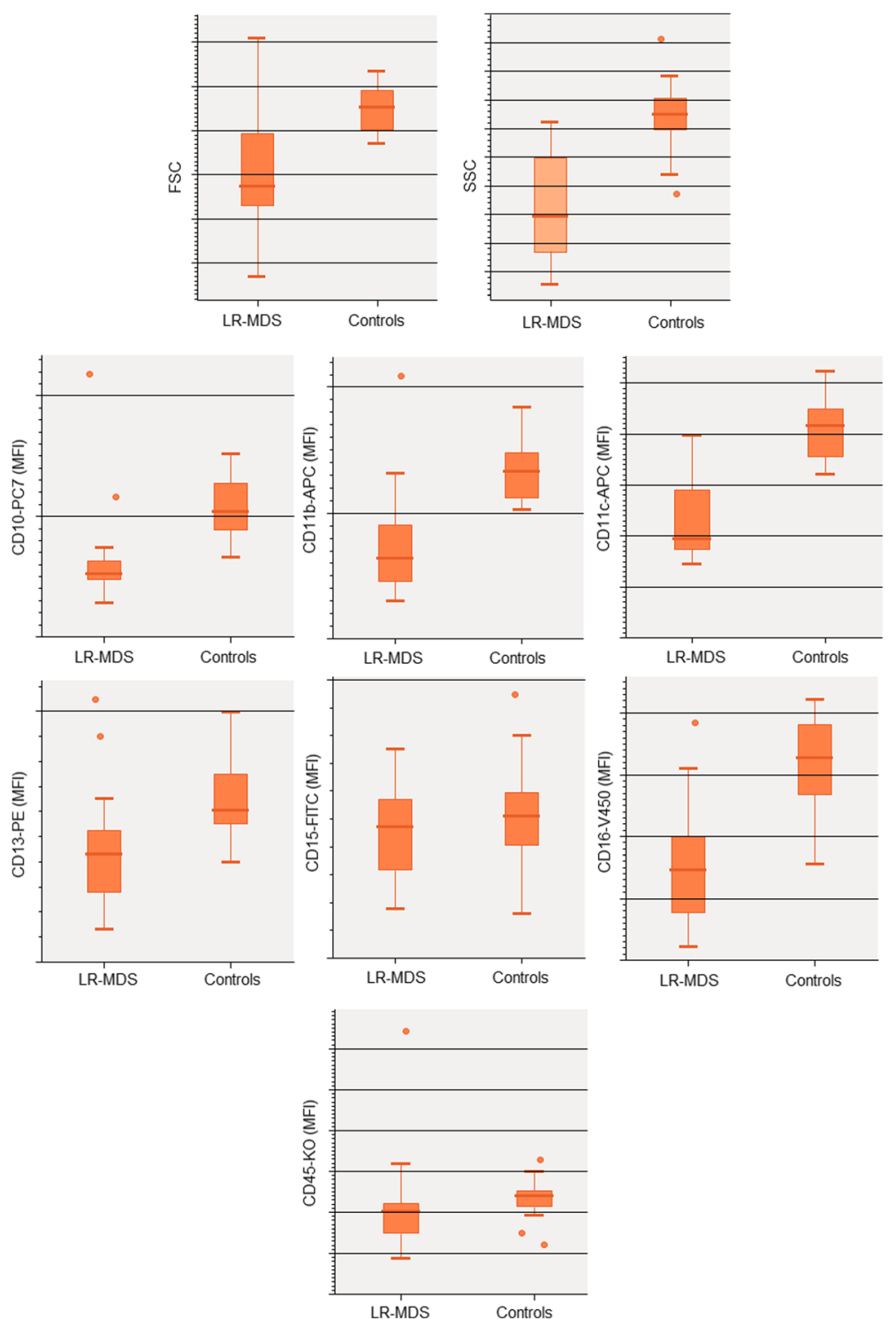

Fig. 2 FSC, SSC and surface antigen expression in PB neutrophils from patients with LR-MDS and healthy individuals (controls). Results as expressed as arbitrary units of fluorescence intensity. Lower whiskers are 1.5 times the Inter-Quartile Range below the lower quartile, or the minimum value, whichever is closest to the middle. Upper whiskers are calculated using the same approach. Outliers are displayed. Abbreviations: FSC, forward scatter; LR-MDS, lower risk myelodysplastic syndromes; MFI, median fluorescence intensity; PB, peripheral blood; SSC, side scatter

Table S3). In the same way, the overall levels of CD13, CD14, CD15, CD45 and CD64 expression on monocytes did not differ significantly from those observed in controls $(\mathrm{p}>0.05)$. However, monocytes from patients with LR-MDS had significantly higher levels of CD56 ( $p=$ 0.006), and lower levels of CD11c ( $p=0.004), \mathrm{CD} 16$ ( $p=$ $0.005)$ and HLA-DR $(p=0.042)$, and showed a tendency for a lower CD11b expression $(p=0.089)$, as compared to controls.

Despite of the above-mentioned differences between monocytes from LR-MDS patients and controls, the individual analysis of the analyzed cell surface markers on monocytes was much less informative than that found in neutrophils, with an abnormal monocyte immunophenotype being found in only a limited number of cases.

One of the most consistent aberrancies found in MDS monocytes consisted in abnormally high levels of CD56 expression, observed in 6 cases (43\%), with increased percentages of $\mathrm{CD} 56^{+}$monocytes. In accordance, monocytes from LR-MDS patients had significantly higher percentages of $\mathrm{CD}^{2} 6^{+}$cells, as compared to normal individuals (median values of $15 \%$ and $7 \%$, ranging from 0 to 99\% and from 0 to $15 \%$, respectively; $p=0.026$ ) (Fig. 5 and Table 5). Increased percentages of $\mathrm{CD} 14^{+} \mathrm{CD} 56^{+}$ monocytes $(>18 \%)$ were found in $6(43 \%)$ MDS patients but in none of the healthy individuals, and in most of 


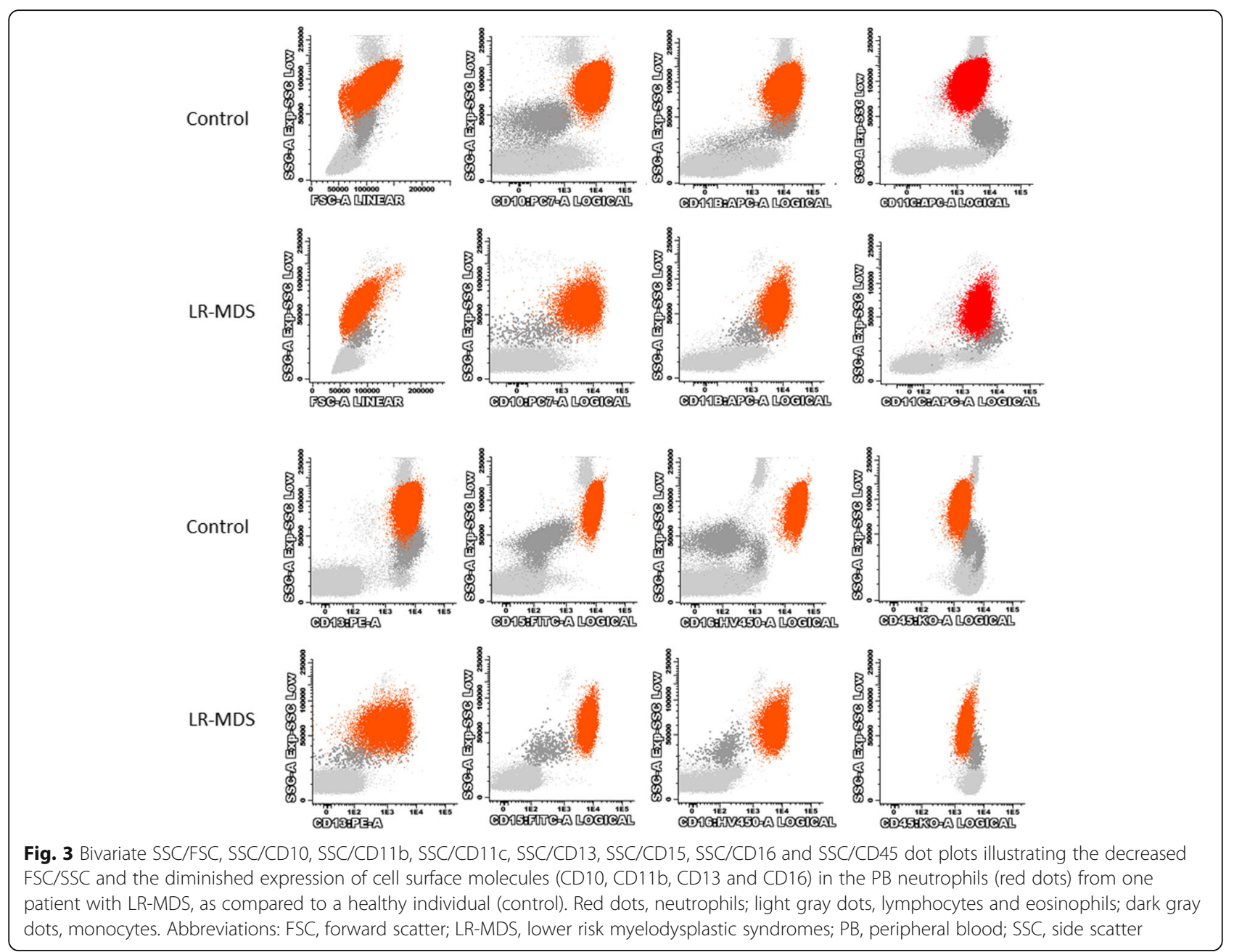

the patients (4, 29\%), $\mathrm{CD} 14^{+} \mathrm{CD} 56^{+}$monocytes were markedly increased (> 28\%). CD56 expression was mainly observed on classical CD $14^{\text {+high }} \mathrm{CD} 16^{-}$monocytes (Fig. 5, panel B).

Another recurrent aberrancy observed in LR-MDS patients consisted in a marked decrease in the fraction of $\mathrm{CD} 14^{+} \mathrm{CD} 16^{+}$monocytes, comparatively to controls (median values of $3 \%$ and $12 \%$, ranging from 0 to $8 \%$ and from 4 to $28 \%$, in patients and in controls, respectively; $p<0.001$ ) (Fig. 5 and Table 5). In overall, 9 patients (64\%) had decreased percentages of $\mathrm{CD} 14^{+} \mathrm{CD} 16^{+}$ monocytes $(<5 \%)$, when compared to only $2(14 \%)$ of the controls. Curiously, the severity of the deficiency was higher in patients than in controls, with $50 \%$ of the patients, but none of the controls, having a moderate $(<2.5 \%)$ or severe $(<1.25 \%)$ deficiencies of $\mathrm{CD} 14^{+} \mathrm{CD} 16^{+}$ monocytes.

Finally, abnormally low CD11b and HLA-DR expression was found in $5(36 \%)$ and $4(28 \%)$ patients, respectively. Less frequent findings included abnormally low levels of CD45 (2 patients, 14\%), and decreased CD11c and CD64 expression (1 case each, 7\%); moreover, abnormally high levels of CD14 and CD64 were found in 2 cases each, and abnormally high levels of CD11b in only 1 case; cases with abnormal CD13 expression were not found.

When the healthy volunteers aged 55 years or over were compared to those who were younger than 55 years, we observed a tendency for a lower intensity of CD14 expression in monocytes $(p=0.064)$, and a higher percentage of proinflammatory $\left(\mathrm{CD} 16^{+}\right)$monocytes in the first group (median values of $13.2 \%$ and $5.9 \%$, respectively; $p=0.035$ ). The other parameters analyzed did not show statistically significant differences between the "youngest" and "oldest" individuals, neither between males and females $(p>0.05)$.

\section{Circulating immature cells}

Immature $\mathrm{CD}^{+} 4^{+}$cells represented $0.15 \pm 0.28 \%$ of the WBC in the PB from LR-MDS patients (median value of $0.05 \%$, ranging from 0.01 to $1.05 \%$ ), as compared to 0.03 $\pm 0.01 \%$ (median value of $0.03 \%$, ranging from 0.01 to 
Table 4 Type and frequency of immunophenotypic aberrancies detected in PB neutrophils from LR-MDS patients versus normal individuals (controls)

\begin{tabular}{|c|c|c|c|c|}
\hline & \multicolumn{2}{|l|}{$\begin{array}{l}\text { LR-MDS } \\
(n=14)\end{array}$} & \multicolumn{2}{|l|}{$\begin{array}{l}\text { Controls } \\
(n=14)\end{array}$} \\
\hline & Decreased & Increased & Decreased & Increased \\
\hline \multicolumn{5}{|c|}{ Abnormal light scatter characteristics } \\
\hline FSC & $10(71 \%)$ & $1(7 \%)$ & $0(0 \%)$ & $0(0 \%)$ \\
\hline SSC & $8(57 \%)$ & $0(0 \%)$ & $0(0 \%)$ & $1(7 \%)$ \\
\hline \multicolumn{5}{|c|}{ Abnormal expression of cell surface markers } \\
\hline CD10 & $9(64 \%)$ & $1(7 \%)$ & $0(0 \%)$ & $0(0 \%)$ \\
\hline CD11b & $10(71 \%)$ & $1(7 \%)$ & $0(0 \%)$ & $1(7 \%)$ \\
\hline CD11c & $10(71 \%)$ & $0(0 \%)$ & $0(0 \%)$ & $0(0 \%)$ \\
\hline CD13 & $4(29 \%)$ & $1(7 \%)$ & $0(0 \%)$ & $0(0 \%)$ \\
\hline CD15 & $0(0 \%)$ & $0(0 \%)$ & $1(7 \%)$ & $1(7 \%)$ \\
\hline CD16 & $6(43 \%)$ & $0(0 \%)$ & $0(0 \%)$ & $0(0 \%)$ \\
\hline CD45 & $2(14 \%)$ & $1(7 \%)$ & $1(7 \%)$ & $0(0 \%)$ \\
\hline \multicolumn{5}{|c|}{ Number of individuals with abnormal parameters } \\
\hline No abnormal parameters & $1(7 \%)$ & $10(71 \%)$ & $12(86 \%)$ & $11(79 \%)$ \\
\hline One abnormal parameter & $0(0 \%)$ & $3(21 \%)$ & $2(14 \%)$ & $3(21 \%)$ \\
\hline Two abnormal parameters & $2(14 \%)$ & $1(7 \%)$ & $0(0 \%)$ & $0(0 \%)$ \\
\hline Three abnormal parameters & $1(7 \%)$ & $0(0 \%)$ & $0(0 \%)$ & $0(0 \%)$ \\
\hline Four abnormal parameters & $3(21 \%)$ & $0(0 \%)$ & $0(0 \%)$ & $0(0 \%)$ \\
\hline Five abnormal parameters & $4(29 \%)$ & $0(0 \%)$ & $0(0 \%)$ & $0(0 \%)$ \\
\hline Six abnormal parameters & $2(14 \%)$ & $0(0 \%)$ & $0(0 \%)$ & $0(0 \%)$ \\
\hline Seven abnormal parameters & $0(0 \%)$ & $0(0 \%)$ & $0(0 \%)$ & $0(0 \%)$ \\
\hline Eight abnormal parameters & $1(7 \%)$ & $0(0 \%)$ & $0(0 \%)$ & $0(0 \%)$ \\
\hline Nine abnormal parameters & $0(0 \%)$ & $0(0 \%)$ & $0(0 \%)$ & $0(0 \%)$ \\
\hline
\end{tabular}

Abbreviations: $L R-M D S$ lower risk myelodysplastic syndromes, $P B$ peripheral blood Results are expressed as absolute and (relative) frequencies

Percentages were approximated to the closest full unit

$0.04 \%)$ in normal individuals. These cells had low SSC and FSC, they were $\mathrm{CD} 45^{\text {+low }}, \mathrm{CD} 34^{+}, \mathrm{CD} 13^{+}, \mathrm{CD} 117$ ${ }^{-/+}$, HLA-DR ${ }^{+}$, and they virtually fail to express all the other molecules analyzed (CD10, CD11b, CD11c, CD15 and CD16) (data not shown).

Patients with MDS also had increased numbers of circulating immature granulocytes (promyelocytes, myelocytes and metamyelocytes) $(1.17 \pm 2.03 \%$, with a median value of $0.36 \%$, ranging from 0.06 to $7.72 \%$ ), as compared to controls $(0.11 \pm 0.06 \%$; median value of $0.11 \%$, ranging from 0.02 to $0.21 \%)$. These cells were $\mathrm{SSC}^{\text {high }}$, FSC ${ }^{\text {high }}, \mathrm{CD} 5^{\text {+low }}, \mathrm{CD} 5^{+}$and $\mathrm{CD}^{+} 4^{+}$, and they had variable and low $\mathrm{CD} 11 \mathrm{~b}$ and $\mathrm{CD} 16$ expression, being negative for the remaining molecules tested (CD10, CD11c, CD13, CD34, CD56, CD117, HLA-DR) (data not shown).

Differences between patients and controls reached statistical significance for circulating immature granulocytes $(p<0.001)$, but not for immature $\mathrm{CD} 34^{+}$cells $(p=0.056)$.

\section{Immunophenotypic scores}

As mentioned above, we defined two FCM-based scorings systems (type 1 and 2) to evaluate dysplasia in neutrophils and monocytes, and, for each scoring system, a total myeloid score was calculated. The results obtained are summarized in Tables 6 and 7, respectively.

\section{Immunophenotypic scoring schema 1 \\ Neutrophil score type 1}

The mean neutrophil score type 1 obtained in LR-MDS patients was of $4 \pm 2$, ranging from " 0 " to 8 (total score rank =59), while all controls had a score of 1 or lower (total score rank $=1$ ), with only 1 case having a score = 1 , corresponding to a normal individual whose neutrophils had dimmer CD45 expression (Table 6). According to this score, four groups of MDS patients were identified: score of "0", no neutrophil dysplasia $(n=1$, corresponding to the patient with a normal neutrophil immunophenotype mentioned above); score of 1 , possible neutrophil dysplasia $(n=0)$; score of between 2 and 

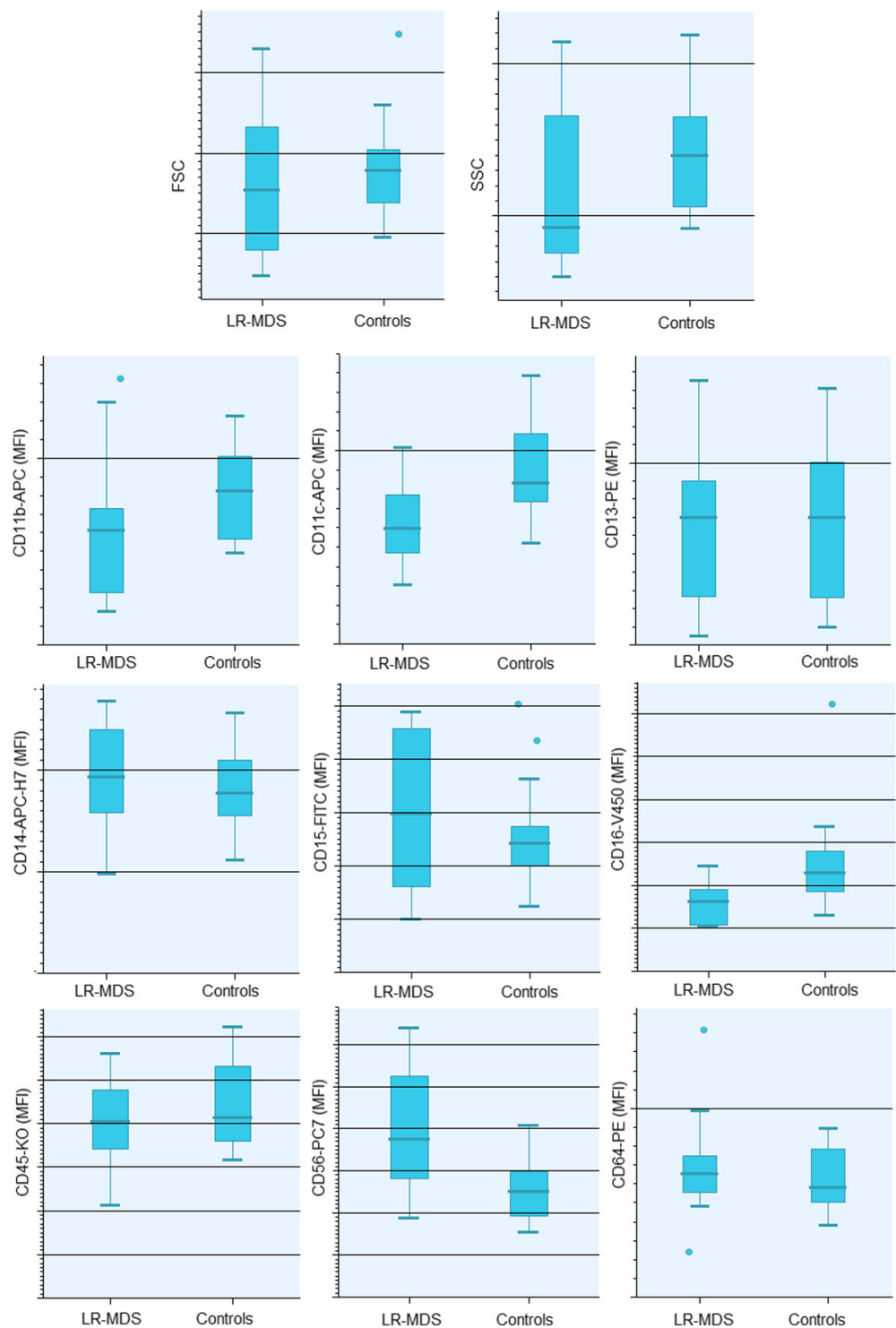

Fig. 4 FSC, SSC and surface antigen expression in PB monocytes from patients with LR-MDS and healthy individuals (controls). Results as expressed as arbitrary units of fluorescence intensity. Lower whiskers are 1.5 times the Inter-Quartile Range below the lower quartile, or the minimum value, whichever is closest to the middle. Upper whiskers are calculated using the same approach. Outliers are displayed. Abbreviations: FSC, forward scatter; LR-MDS, lower risk myelodysplastic syndromes; MFI, median fluorescence intensity; PB, peripheral blood; SSC, side scatter

3 , mild neutrophil dysplasia $(n=3 ; 21 \%)$; score between 4 and 6, moderate neutrophil dysplasia $(n=9 ; 64 \%)$; and score over 6 , severe neutrophil dysplasia $(n=1 ; 7 \%)$. Thus, assuming a cut-off of $>1$ points we correctly classified 13 out of 14 LR-MDS patients and 14 out of 14 controls, given a sensitivity of $93 \%$ and a specificity of $100 \%$ for the diagnosis of MDS.

\section{Monocyte score type 1}

The monocytic score type 1 obtained in LR-MDS patients ranged from 0 to 2 (median 1 ; mean \pm SD of $1 \pm 1$ ), whereas the score observed in controls ranged from 0 to 1 (Table 6). The total score rank for these groups was of 15 and 2, respectively. Using this score, four groups of MDS patients were identified: score of " 0 ", no monocyte dysplasia $(n=2 ; 14 \%)$; score of 1 , possible monocyte dysplasia $(n=8 ; 57 \%)$; and score of 2 , monocyte dysplasia $(n=4 ; 29 \%)$. Comparatively, 12 out of 14 controls ( $86 \%$ ) had a score of "0", and the remaining 2 cases had a score of 1 , due to moderate decrease in the fraction of $\mathrm{CD} 14^{+} \mathrm{CD} 16^{+}$monocytes (4.9\% and $4.1 \%$ of total monocytes, respectively). Consequently, assuming a cut-off of $\geq 1$ points we correctly categorized 12 out of 14 LR-MDS patients and 12 out of 14 controls, given a sensitivity and a specificity of $86 \%$ for the diagnosis of MDS. 


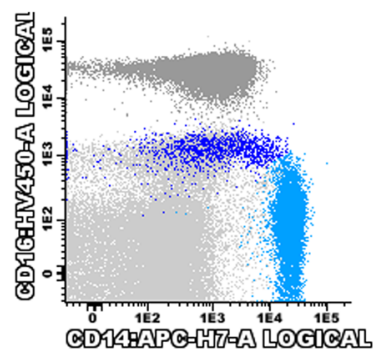

Control

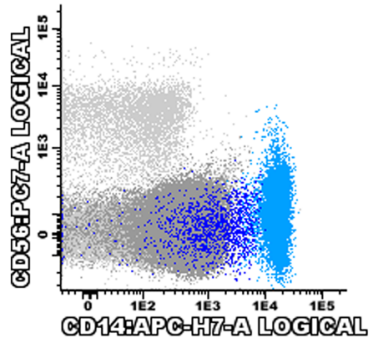

Control

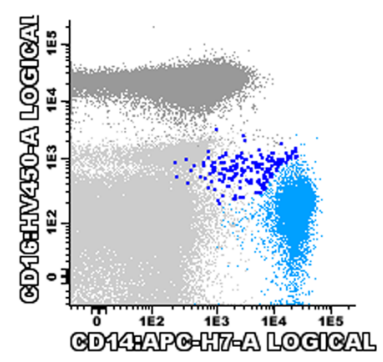

LR-MDS

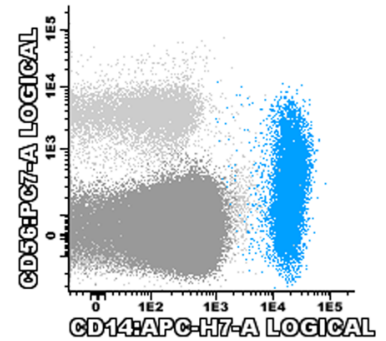

LR-MDS

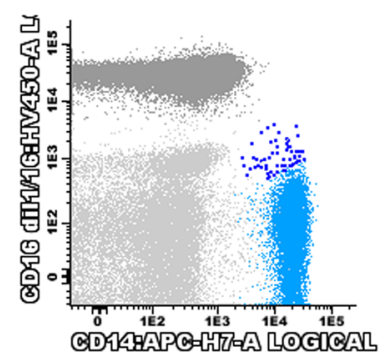

LR-MDS

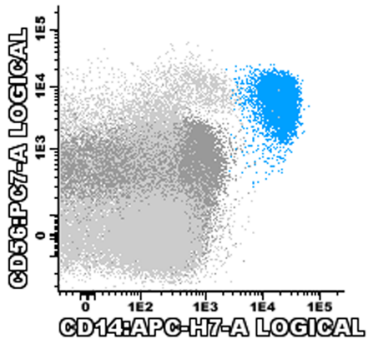

LR-MDS

Fig. 5 Bivariate CD16/CD14 and CD56/CD14 dot plots illustrating the depletion of non-classical (intermediate CD $14^{\text {+high }}$ CD $16^{+}$plus proinflammatory $\mathrm{CD} 14^{\text {+low }} \mathrm{CD} 16^{+}$) monocytes (upper row) and the aberrant CD56 expression in the PB classical CD14 ${ }^{\text {thigh }} \mathrm{CD} 16^{-}$monocytes (lower row) from two patients with LR-MDS, as compared to a normal individual (control). Light blue dots, classical CD14 ${ }^{\text {thigh }}$ CD $16^{-}$monocytes; dark blue dots, non-classical (intermediate $\mathrm{CD} 14^{+ \text {high }} \mathrm{CD} 16^{+}$plus proinflammatory $\mathrm{CD} 14^{+ \text {low }} \mathrm{CD} 16^{+}$) monocytes; light gray dots, lymphocytes and eosinophils; dark gray dots, neutrophils. Abbreviations: FSC, forward scatter; LR-MDS, lower risk myelodysplastic syndromes; PB, peripheral blood; SSC, side scatter

\section{Myeloid score type 1}

Considering the total myeloid score type 1 , obtained by the sum of the correspondent neutrophil and monocytic scores, we found a score of $5 \pm 2$ for LR-MDS (median of 6 , ranging from 0 to 8 ), while all controls had a score of 1 or under (Table 6). According to this score, four groups of MDS patients were identified: score of "0" (no myelodysplasia) ( $n=1 ; 7 \%$, corresponding to the patient mentioned above); score of 1 (possible myelodysplasia) $(n=0)$; score of between 2 and $4(n=3 ; 21 \%)$ (mild

Table 5 Immunophenotypic alterations detected in PB monocytes from LR-MDS patients versus normal individuals (controls)

\begin{tabular}{|c|c|c|}
\hline & $\begin{array}{l}\text { LR-MDS } \\
(n=14)\end{array}$ & $\begin{array}{l}\text { Controls } \\
(n=14)\end{array}$ \\
\hline \multicolumn{3}{|l|}{ Increased CD56 expression in monocytes } \\
\hline $\mathrm{CD}_{14}{ }^{+} \mathrm{CD} 56^{+}$cells (\% total CD $14^{+}$monocytes) $\left(^{*}\right)$ & $15(0-99)$ & $7(0-15)$ \\
\hline Increased percentages of $\mathrm{CD} 14^{+} 56^{+}$cells (> $18.0 \%$ total CD14 $4^{+}$monocytes) & $6(43 \%)$ & $0(0 \%)$ \\
\hline \multicolumn{3}{|l|}{ Severity } \\
\hline Mild: CD56 ${ }^{+}$cells]18\%-23\%] & $1(7 \%)$ & $0(0 \%)$ \\
\hline 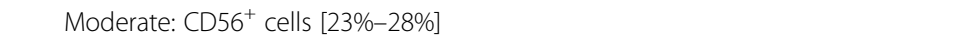 & $1(7 \%)$ & $0(0 \%)$ \\
\hline Severe: CD56 ${ }^{+}$cells]28\%-100\%] & $4(29 \%)$ & $0(0 \%)$ \\
\hline \multicolumn{3}{|l|}{ Decreased CD16 expression in monocytes } \\
\hline $\mathrm{CD}_{14}^{+} \mathrm{CD} 16^{+}$cells (\% total CD $14^{+}$monocytes) $\left.{ }^{(* *}\right)$ & $3(0-8)$ & $12(4-28)$ \\
\hline Decreased percentages of $\mathrm{CD} 14^{+} \mathrm{CD} 16^{+}$cells $\left(<5.0 \%\right.$ of total $\mathrm{CD} 14^{+}$monocytes) & $9(64 \%)$ & $2(14 \%)$ \\
\hline \multicolumn{3}{|l|}{ Severity } \\
\hline Mild: CD16 ${ }^{+}$cells $[2.5 \%-5.0 \%]$ & $2(14 \%)$ & $2(14 \%)$ \\
\hline Moderate: $\mathrm{CD} 16^{+}$cells [1.25-2.5\%] & $1(7 \%)$ & $0(0 \%)$ \\
\hline Severe: CD16 ${ }^{+}$cells [0.00-1.25\%] & $6(43 \%)$ & $0(0 \%)$ \\
\hline
\end{tabular}

Abbreviations: $L R-M D S$ lower risk myelodysplastic syndromes, $P B$ peripheral blood

Results are expressed as absolute and (relative) frequencies or as median (range) values

Percentages were approximated to the closest full unit

Mann-Whitney $U$ test, LR-MDS patients versus controls: $\left(^{*}\right) P=0.026 ;\left(^{* *}\right) P<0.001$ 
Table 6 Neutrophil and monocyte immunophenotypic scores, and total myeloid score for myelodysplasia in the PB from LR-MDS patients versus normal individuals (controls), taking in account the number of phenotypic abnormalities found in each case

\begin{tabular}{|c|c|c|}
\hline & $\begin{array}{l}\text { LR-MDS } \\
(n=14)\end{array}$ & $\begin{array}{l}\text { Controls } \\
(n=14)\end{array}$ \\
\hline \multicolumn{3}{|c|}{ Neutrophil immunophenotypic score $1(0-8)$} \\
\hline Score & $5(0-8)$ & $0(0-1)$ \\
\hline Score rank $(\Sigma)$ & 59 & 1 \\
\hline \multicolumn{3}{|l|}{ Score classes } \\
\hline 0 (no dysplasia) & $1(7 \%)$ & $13(93 \%)$ \\
\hline 1 (possible dysplasia) & $0(0 \%)$ & $1(7 \%)$ \\
\hline 2-3 (mild dysplasia) & $3(21 \%)$ & $0(0 \%)$ \\
\hline 4-6 (moderate dysplasia) & $9(64 \%)$ & $0(0 \%)$ \\
\hline 7-8 (severe dysplasia) & $1(7 \%)$ & $0(0 \%)$ \\
\hline \multicolumn{3}{|c|}{ Monocyte immunophenotypic score 1 (0-2) } \\
\hline Score & $1(0-2)$ & $0(0-1)$ \\
\hline Score rank $(\Sigma)$ & 15 & 2 \\
\hline \multicolumn{3}{|l|}{ Score classes } \\
\hline 0 (no dysplasia) & $2(14 \%)$ & $12(86 \%)$ \\
\hline 1 (possible dysplasia) & $8(57 \%)$ & $2(14 \%)$ \\
\hline 2 (dysplasia) & $4(29 \%)$ & $0(0 \%)$ \\
\hline \multicolumn{3}{|c|}{ Myeloid immunophenotypic score $1(0-10)$} \\
\hline Score & $6(0-8)$ & $0(0-1)$ \\
\hline Score rank $(\Sigma)$ & 74 & 3 \\
\hline \multicolumn{3}{|l|}{ Score classes } \\
\hline 0 (no dysplasia) & $1(7 \%)$ & $11(79 \%)$ \\
\hline 1 (possible dysplasia) & $0(0 \%)$ & $3(21 \%)$ \\
\hline 2-4 (mild dysplasia) & $3(21 \%)$ & $0(0 \%)$ \\
\hline 5-7 (moderate dysplasia) & $7(50 \%)$ & $0(0 \%)$ \\
\hline 8-10 (severe dysplasia) & $3(21 \%)$ & $0(0 \%)$ \\
\hline
\end{tabular}

Abbreviations: $L R-M D S$ lower risk myelodysplastic syndromes, $P B$ peripheral blood

Results are expressed as absolute and (relative) frequencies or as median (range) values

Percentages were approximated to the closest full unit

Neutrophil score: The following parameters were considered: FSC, SSC, CD10, CD11b, CD11C, CD13, CD16, and CD45. Each abnormally low parameter ( $<$ mean $-2 D$ of the values observed in controls) was scored with 1 point. Values within the mean $\pm S D$ or above the mean $+2 S D$ were scored with "0"

Monocyte score: The following parameters were considered: \% of CD16+ monocytes and \% of CD56+ monocytes. These parameters were scored as follows: CD14 + CD56+ monocytes: $\leq 18 \%$ ( 0 points); $>18 \%$ ( 1 point); CD14 + CD16+ monocytes: $\geq 5 \%$ (0 points); $<5 \%$ (1 point)

Myeloid score: obtained by adding up the neutrophil and the monocytic score achieved for each patient

The following score rankings were obtained for each of the parameters analyzed: Patients: $\mathrm{FSC}=10 ; \mathrm{CD} 11 \mathrm{~b}=10 ; \mathrm{CD} 11 \mathrm{C}=10 ; \mathrm{CD} 10=9 ; \mathrm{SSC}=8$; $\mathrm{CD} 13=4 ; \mathrm{CD} 15=0 ; \mathrm{CD} 16=6 ; \mathrm{CD} 45=2$. Controls: $\mathrm{CD} 15=1 ; \mathrm{CD} 45=1$; other parameters $=0$
Table 7 Neutrophil and monocyte immunophenotypic scores, and total myeloid score for myelodysplasia in the PB from LR-MDS patients versus normal individuals (controls), taking in account the number and the severity of the phenotypic abnormalities found in each case

\begin{tabular}{lll}
\hline & $\begin{array}{c}\text { LR-MDS } \\
(\mathrm{n}=14)\end{array}$ & $\begin{array}{l}\text { Controls } \\
(\mathrm{n}=14)\end{array}$ \\
\hline $\begin{array}{l}\text { Neutrophil immunophenotypic score 2 }(0-8) \\
\text { Score }\end{array}$ & $2(0-3)$ & $0(0-0)$ \\
Score rank $(\Sigma)$ & 28 & 0 \\
Score classes & & $14(100 \%)$ \\
0 (no dysplasia) & $1(7 \%)$ & $0(0 \%)$ \\
1 (possible dysplasia) & $2(14 \%)$ & $0(0 \%)$ \\
2-3 (mild dysplasia) & $11(79 \%)$ & $0(0 \%)$ \\
4-6 (moderate dysplasia) & $0(0 \%)$ & $0(0 \%)$ \\
$7-8$ (severe dysplasia) & $0(0 \%)$ &
\end{tabular}

Monocyte immunophenotypic score 2 (0-2)

Score

$1(0-2)$

$0(0-0)$

Score rank $(\Sigma)$

12

Score classes

$\begin{array}{lll}0 \text { (no dysplasia) } & 5(36 \%) & 14(100 \%) \\ 1 \text { (probable dysplasia) } & 6(43 \%) & 0(0 \%) \\ 2 \text { (dysplasia) } & 3(21 \%) & 0(0 \%)\end{array}$

Myeloid immunophenotypic score $2(0-10)$

Score

$3(0-5)$

$0(0-1)$

Score rank $(\Sigma)$

39

Score classes

$\begin{array}{lll}0 \text { (no dysplasia) } & 1(7 \%) & 14(0 \%) \\ 1 \text { (possible dysplasia) } & 1(7 \%) & 0(0 \%) \\ 2-4 \text { (mild dysplasia) } & 11(79 \%) & 0(0 \%) \\ 5-7 \text { (moderate dysplasia) } & 1(7 \%) & 0(0 \%) \\ 8-10 \text { (severe dysplasia) } & 0(0 \%) & 0(0 \%)\end{array}$

Abbreviations: $L R-M D S$ lower risk myelodysplastic syndromes, $P B$ peripheral blood

Results are expressed as absolute and (relative) frequencies or as median (range) values

Percentages were approximated to the closest full unit

Neutrophil score: The following parameters were considered: FSC, SSC, CD10,

CD11b, CD11C, CD13, CD16, and CD45. Values within the mean \pm SD or above the mean $+2 S D$ were scored with " 0 ". Abnormally low parameter $(<$ mean-2D of the values observed in controls) were scored as follows: ( $<$ mean-2D: 0.25 points; < mean-3SD: 0.5 points; < mean-3SD: 1 point

Monocyte score: The following parameters were considered: \% of CD16+ monocytes and \% of CD56+ monocytes. These parameters were scored as follows: CD14 + CD $56+$ monocytes: $\leq 18 \%$ (0 points); >mean + 2SD (18\%): 0.25 points; > mean + 3SD (23\%): 0.5 points; > mean + 4SD (28\%): 1 point. CD14 + CD16+ monocytes: $\geq 5 \%$ : 0 points; CD14 + CD16+ monocytes < 5\%: 0.25 point; CD14 + CD16+ monocytes: $<2.5 \%: 0.5$ points; CD14 + CD16+ monocytes: < 1.25\%: 1 point

Myeloid score: obtained by adding up the neutrophil score 1 and the monocytic score achieved for each patient

The following score rankings were obtained for each of the parameters analyzed: Patients: $\mathrm{FSC}=6.5 ; \mathrm{CD} 11 \mathrm{c}=5.5 ; \mathrm{CD} 11 \mathrm{~b}=5.0 ; \mathrm{SSC}=4.5 ; \mathrm{CD} 10=2.5$; $\mathrm{CD} 16=2 ; \mathrm{CD} 13=1.0 ; \mathrm{CD} 15=0.0 ; \mathrm{CD} 45=0.5$. Controls: $\mathrm{CD} 15=0.25 ; \mathrm{CD} 45=0.25$; other parameters $=0$ 
myelodysplasia); score between 5 and 7 (moderate myelodysplasia) ( $n=7 ; 50 \%)$; and score over 8 (severe myelodysplasia) $(\mathrm{n}=3 ; 21 \%)$. In contrast, in the control group, most of the individuals had a score of " 0 ", with only 3 (21\%) having a score of 1 . Therefore, assuming a cut-off of $\geq 2$ points we were able to correctly classify 13 out of 14 LR-MDS patients and 14 out of 14 controls, given a sensitivity of $93 \%$ and a specificity of $100 \%$ for the diagnosis of MDS.

\section{Immunophenotypic scoring schema 2 Neutrophil score type 2}

The mean neutrophil score type 2 obtained in LR-MDS patients was of $2 \pm 1$, ranging from 0 to 3 (total score rank $=28$ ), while all controls had a score of "0" (Table 7). According to this score, four groups of MDS patients were identified: score of " 0 ", no dysplasia $(\mathrm{n}=1 ; 7 \%)$; ii) score of $1(n=2 ; 14 \%)$; score between 2 and $3(n=1$; $7 \%)$; score between 4 and $6(\mathrm{n}=0)$; and score over 6 $(\mathrm{n}=0)$. Thus, similarly to that observed with the neutrophil scoring system type 1 , assuming a cut-off of $>1$ points we were able to correctly classify 13 out of 14 LR-MDS patients and 14 out of 14 controls (sensitivity of $93 \%$ and specificity of $100 \%$ for the diagnosis of MDS).

\section{Monocyte score type 2}

The mean monocyte score type 2 obtained in LR-MDS patients was of $1 \pm 1$, ranging from 0 to 2 (total score rank $=12$ ), whereas the score observed in controls was of "0" in all cases (Table 7). According this score, four groups of MDS patients were identified: score of " 0 " $(n=5 ; 36 \%)$; score of $1(n=6 ; 43 \%)$; and score of 2 $(\mathrm{n}=3 ; 21 \%)$. Comparatively, all controls had a score of " 0 ". Consequently, assuming a cut-off of $\geq 1$ point we were able to correctly classify 9 out of 14 LR-MDS patients and all controls, given a sensitivity and a specificity of $64 \%$ for the diagnosis of MDS.

\section{Myeloid score type 2}

Considering the total myeloid score type 2, i.e. the sum of the neutrophil and monocytic scores type 2, we obtained a score of $3 \pm 1$ for LR-MDS (median of 3, ranging from 0 to 8 , total score rank=39), while all controls had a score of 1 or under (Table 7).

As a result, the scoring schemas type 2 apparently do not offer advantages for the diagnosis of myelodysplasia, as compared to the scoring schemas type 1, which are more easily to calculate.

\section{MDS thermometers}

The immunophenotypic scoring schemas type 1 were used to conceive the MDS Thermometer tool, aimed for the screening of MDS in PB samples in clinical practice, which can be deployed on two thermometers, for neutrophils and monocytes, respectively (Fig. 6). The neutrophil thermometer is based on the neutrophil score system type 1, i.e., the number of cell surface markers abnormally low expressed in neutrophils, among 8 parameters considered (FSC, SSC, CD10, CD11b, CD11c, CD13, CD16 and CD45). The monocyte thermometer is based on the monocyte scoring system type 1, i.e., increased fraction of $\mathrm{CD}_{56}{ }^{+}$cells (aberrant CD56 expression) and decreased fraction of $\mathrm{CD} 6^{+}$cells (depletion of proinflammatory monocytes) among total monocytes. The myeloid thermometer was obtained by the sum of the neutrophil and the monocyte type 1 scores.

\section{Discussion}

Progresses made in the last years concerning the assessment of MDS by FCM have led to consensus recommendations for the integration of FCM data in the diagnostic work-up of MDS [21]. However, establishing the diagnosis still requires $\mathrm{BM}$ aspirate and biopsy, which are invasive procedures and not always conclusive, especially in LR-MDS.

Given the frequency of MDS patients with mild cytopenias that would not demand therapeutic intervention, due the fact that most MDS patients are not eligible for intensive treatment schedules, and taking into account the easy access to PB samples, it would be desirable to have a PB assay to help guide the need for invasive $\mathrm{BM}$ evaluation. Nonetheless, immunophenotypic studies in the PB from patients with MDS are surprisingly scarce. Using the PubMed and applying the key words "flow cytometry", "myelodysplastic syndromes", and "peripheral blood", we found only five studies performed in the PB [27-31].

Cherian et al. (2005) observed that neutrophils from MDS patients had lower SSC and higher expression of CD66 and CD11a than did controls; in some cases, PB neutrophils also displayed abnormal CD116 and CD10 expression [27, 28]. Using these markers, they proposed a score that allowed to distinguish MDS patients from normal controls with a sensitivity of $73 \%$ and a specificity of $90 \%$ [28].

Some years later (2012), using 3-color FCM, Rashidi et al. observed that CD10 expression on PB neutrophils was significantly decreased in patients with HR-MDS and CMML compared to both non-MDS patients with pancytopenia and to LR-MDS patients [30]. In contrast, they found no significant differences in CD11b, CD13, CD14, CD16, CD33, CD56, and CD64 expression in neutrophils and monocytes from the mentioned groups of patients.

More recently (2013), Meyerson et al. realized that low CD177 expression was frequent in PB and BM neutrophils from patients with clonal myeloid disorders; these findings were most pronounced in MDS, with $52 \%$ of cases containing less than $40 \%$ of $\mathrm{CD} 177^{+}$neutrophils [31]. 


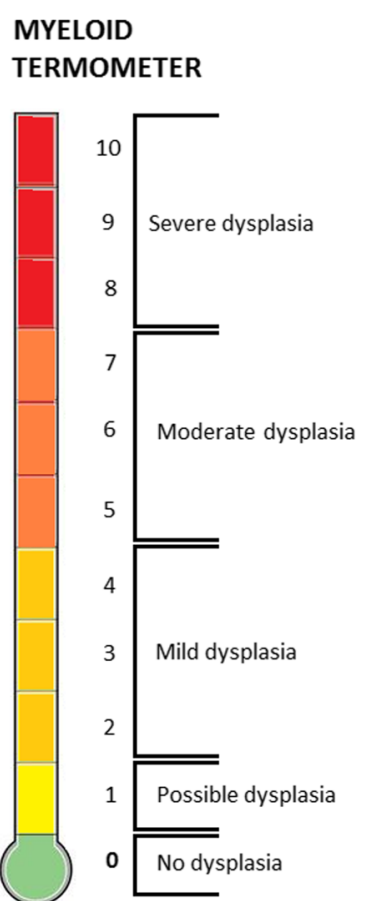

\section{NEUTROPHIL}

THERMOMETER

\author{
FSC, SSC \\ CD10, CD11b, CD11c, $\downarrow$
}

$\mathrm{CD} 13, \mathrm{CD} 16, \mathrm{CD} 45$
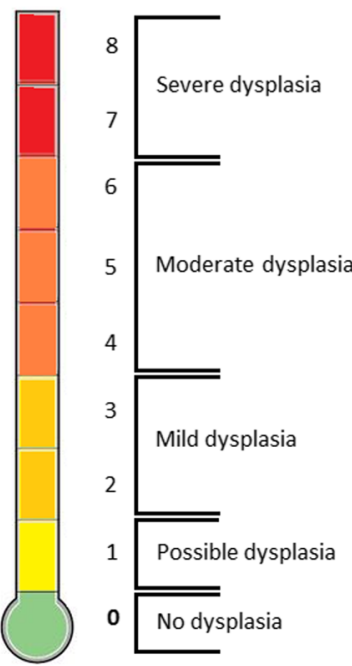

MONOCYTE

THERMOMETER

Fig. 6 MDS Thermometers. The neutrophil thermometer is based on the neutrophil score system type 1, i.e., the number of cell surface markers abnormally low expressed in PB neutrophils, among 8 parameters considered (FSC, SSC, CD10, CD11b, CD11C, CD13, CD16 and CD45). The monocyte thermometer is based on the monocyte scoring system type 1, i.e., increased fraction of CD56 ${ }^{+}$cells (aberrant CD56 expression) and decreased fraction of $\mathrm{CD}_{16} 6^{+}$cells (depletion of proinflammatory monocytes) among total PB monocytes. The myeloid thermometer was obtained by the sum of the neutrophil and the monocyte type 1 scores. Abbreviations: FSC, forward scatter; PB, peripheral blood; SSC, side scatter

Altered immunophenotypic features of PB platelets, consisting of abnormal light scatter characteristics, over or under expression of platelet glycoproteins and asynchronous CD34 expression were also described in patients with MDS [29].

Our pilot study revealed, for the first time, that PB neutrophils from LR-MDS not only frequently have decreased FSC and/or SSC, but also commonly display abnormally low levels of CD11b, CD11c, CD10, CD16, CD13 and CD45 expression, as compared to normal neutrophils. The fact that $93 \%$ of these patients had abnormally low levels of 2 or more (out of 9) cell surface molecules on neutrophils, as compared to only $29 \%$ having abnormal morphology, clearly indicates that FCM is more sensitive for the detection of myelodysplasia in the PB than cytomorphology. In addition, we observed a marked deficiency in proinflammatory $\mathrm{CD} 6^{+}$monocytes and a high frequency of CD56 expression in circulating monocytes from patients with LR-MDS, irrespectively of the monocyte counts.

Human PB monocytes have been divided into distinct subsets, referred to as classical $\left(\mathrm{CD} 14^{+} \mathrm{CD} 16^{-}\right)$and nonclassical $\left(\mathrm{CD} 14^{+} \mathrm{CD} 16^{+}\right)$monocytes; in between, there are "intermediate" monocytes, which are transitional cells for review see [45-48]. $\mathrm{CD} 14^{+} \mathrm{CD} 16^{+}$monocytes, which were first described in the late 80 [49], account for about
$10 \%$ of total PB monocytes in healthy adults and appear to be more mature; they express lower levels of CD14 and higher levels of HLA-DR (CD14 ${ }^{\text {+low }}$ CD $16^{+}$HLA-DR ${ }^{\text {thigh }}$ ) as compared with classical (CD14 $\left.{ }^{\text {+high }} \mathrm{CD} 16^{-} \mathrm{HLA}-\mathrm{DR}{ }^{\text {low }}\right)$ monocytes [50], and they have distinct patterns of cytokines and chemokine receptors. Specifically, $\mathrm{CD} 14^{+} \mathrm{CD} 16^{+}$ monocytes have been shown to efficiently produce tumor necrosis factor (TNF), while they produce no or less of the anti-inflammatory cytokine interleukin (IL)-10 [51, 52]. In opposition to classical monocytes, they lack surface expression of CC chemokine receptor type 2 (CCR2), the receptor for monocyte chemotactic protein-1 (MCP-1), and have higher surface expression of CCR5, the receptor for macrophage inflammatory protein 1 alpha (MIP1alpha) /regulated on activation, normal $\mathrm{T}$ cell expressed and secreted (RANTES) chemokine [53]. Their numbers are increased in various pathological conditions, such as HIV infection [54], sepsis [55], inflammatory bowel diseases [56], other inflammatory and autoimmune conditions [57], and tumors [58, 59], and they have been associated with acute or chronic inflammation. In addition, the relative and absolute numbers of the 'non-classical' CD14 ${ }^{+} \mathrm{CD} 16^{+}$monocytes increase with the age [60].

Herein we described, for the first time, a depletion of proinflammatory $\left(\mathrm{CD} 14^{+} \mathrm{CD} 16^{+}\right)$monocytes, with consequent increase in the fraction of classical $\left(\mathrm{CD} 14^{+} \mathrm{CD} 16^{-}\right)$ 
monocytes, in the PB of LR-MDS patients. This finding may explain the abnormally low levels of CD11c, CD16 and HLA-DR expression we observed in PB monocytes from patients with LR-MDS. The reasons for this abnormal repartition of the PB monocyte subsets observed in patients with MDS are not clear. Patients included were not medicated with corticosteroids, which are known to induce a selective depletion of the $\mathrm{CD} 14^{+} \mathrm{CD} 16^{+}$monocytes [61]. Also, it cannot be explained by aging, as in healthy individuals, proinflammatory $\mathrm{CD} 14^{+} \mathrm{CD} 16^{+}$monocytes significantly increase with age, as we observed in our control group. Maybe this is a consequence of a defective monocyte maturation, as already described for CMML [62]. Curiously, Selimoglu-Buet et al. have recently found an increase in the fraction of classical $\mathrm{CD} 14^{+} \mathrm{CD} 16^{-}$monocytes, in the PB from patients with CMML, as compared to healthy individuals and to patients with reactive monocytosis [18]. Taking in account that, as stated above, an opposite abnormal repartition of the mentioned monocyte subsets, with increased fractions of $\mathrm{CD} 16^{+}$monocytes, has been described in inflammatory and autoimmune conditions [56, 57], infections [54, 55, 57, 63], and cancer [58, 59], the selective depletion of $\mathrm{CD} 14^{+} \mathrm{CD} 16^{+}$monocytes in the PB would probably be important for the differential diagnosis between MDS and non-MDS cytopenias.

Abnormal CD56 expression in BM monocytes has already been described in patients with MDS, being observed with higher frequency in HR-MDS, as compared to LR-MDS [64], and is also a frequent in CMML $[17,20,64]$, although these findings are not completely understood.

In healthy individuals, around $10 \%$ of the monocytes coexpress CD56, with the majority of $\mathrm{CD}^{+} 6^{+}$monocytes being CD $14^{\text {+high }}[65,66]$. CD $56^{+}$monocytes are expanded in aging individuals as well as in patients with autoimmune and inflammatory conditions, such as rheumatoid arthritis and inflammatory bowel diseases $[66,67]$. Compared to $\mathrm{CD} 56^{-}$monocytes, $\mathrm{CD} 56^{+}$monocytes spontaneously produce more reactive oxygen intermediates and, upon stimulation, they are stronger producers of cytokines, such as TNF, IL-10 and IL-23 [66]. As so, CD56 expression was recognized as a signal of monocyte activation and/or immunosenescence [66]. Considering the simultaneous decreased fractions of $\mathrm{CD} 14^{+ \text {low }} \mathrm{CD} 16^{+}$and increased fractions of $\mathrm{CD} 14^{+ \text {high }} \mathrm{CD} 56^{+}$monocytes observed in MDS patients, we postulate that blockage of differentiation of classical $\left(\mathrm{CD} 14^{\text {+high }} \mathrm{CD}^{-} 6^{-}\right)$into proinflammatory (CD14 ${ }^{+ \text {low }} \mathrm{CD} 16^{+}$) monocytes leads to accumulation of the first monocyte population in the $\mathrm{PB}$, which becomes senescent and then acquire CD56 expression.

The phenotypic aberrancies observed in the PB from patients with LR-MDS are consistent with those that have been previously described in the $\mathrm{BM}$, and the 2-tubes/8-color panel we proposed for the screening of myelodysplasia in the $\mathrm{PB}$ would allow to evaluate most of the aberrant immunophenotypic features that have been suggested being included in BM studies for the diagnostic work-up of patients with MDS [13, 21]. The exceptions are lineage infidelity markers and some myeloid-associated markers, which are not evaluated with our protocol. In addition, our FCM panel can also be used to quantify and characterize the immature $\mathrm{CD}_{4} 4^{+}$cells, both in the PB and BM samples. For the evaluation of the myeloid and lymphoid compartments in $\mathrm{CD} 34^{+}$BM cells, CD19 may be used instead of CD15, as this marker did not prove to be useful for the diagnosis of neutrophil dysplasia.

Several FCM scoring schemas have been already proposed for diagnosis and prognosis evaluation in MDS, most of them based on the immunophenotypic features of the BM blast cells and on the abnormal immunophenotypic patterns found in maturing myeloid cells $[10,12$, 68]. However, due to the complexity of BM analysis, these schemas are difficult to apply in routine clinical practice. To become clinically applicable, FCM should be not only sensitive and specific, but also reproducible, and the results should be easily understood by clinicians. Therefore, our study fills a gap and refine the accuracy to detect myelodysplasia in the PB.

The visual analogue scale we propose for the screening of myelodysplasia in PB samples - the MDS thermometer, is simple, intuitive and easy to apply. It is based on FCM analysis of 10 parameters, 8 in neutrophils (FSC, SSC, CD10, CD11b, CD11c, CD16, CD45) and 2 in monocytes (CD16, CD56), and it allows to distinguish LR-MDS peripheral blood samples from normal PB samples with a sensitivity of $100 \%$ and a specificity of $93 \%$. It could be argued that it does not take into account the severity of the deficiency of each molecule observed in myelodysplastic cells. However, the alternative scoring schema that evaluates this aspect but is more difficult to apply, did not improve the performance of the test; maybe it can be useful in specific cases. With the necessary adaptations, the concept of the MDS Thermometer could probably also be applied to the MDS/MPN, such as CMML, in which monocytic aberrancies are expected to be more pronounced.

There are some limitations to the current study. First, the number of cases studied is small and this study should be considered a pilot study. Secondly, due to the difficulties in finding blood donors older than 60 years, we were not able to pair healthy controls and MDS patients for age, and it could be argued that differences between groups may be age-related; however, the fact that no differences were found in the analyzed parameters when younger and older healthy volunteers were compared, except for a higher fraction of $\mathrm{CD} 16^{+}$monocytes in the last group, strongly argue against this possibility. 
Thirdly, we did not study non-MDS patients with cytopenias. Finally, attention should be given to the cytometer setup, calibration and stability, and each center should establish its own normal reference values, on the basis of the mAbs and experimental conditions used.

\section{Conclusions}

Our pilot study reveals an altered neutrophil immunophenotype, often accompanied by an abnormal monocyte immunophenotype, in the PB from nearly all LRMDS cases, and suggests that assessment of abnormal antigen expression in PB mature myeloid cells may help to identify patients with LR-MDS. Once translated into a straightforward FCM-based score and converted into a visual analogue scale - MDS thermometer -, these findings can be easily applied in clinical practice. However, due to the low number of cases analyzed, further studies with larger series of patients are needed to confirm our preliminary observations. Furthermore, it would be interesting to evaluate HR-MDS patients, as well as CMML and other MDS/MPN. Additional studies are also required in order to evaluate the specificity of such alterations for the diagnosis MDS, by testing other pathological conditions associated with cytopenias.

\section{Additional files}

Additional file 1: Table S1. Clinical and laboratorial characteristics of the study population, at diagnosis. Peripheral blood and BM findings at diagnosis, and previous treatments. (DOCX $18 \mathrm{~kb}$ )

Additional file 2: Table S2. FSC and SSC values and MedFI of expression of the molecules under study on neutrophils from patients with LR-MDS, as compared to controls. Median (and range) values of the MedFI obtained for each parameter analyzed by FCM in PB neutrophils from LR-MDS patients and healthy controls. (DOCX $14 \mathrm{~kb}$ )

Additional file 3: Table S3. FSC and SSC values and MedFI of expression of the molecules under study on monocytes from patients with LR-MDS, as compared to controls. Median (and range) values of the MedFI obtained for each parameter analyzed by FCM in PB monocytes from LR-MDS patients and healthy controls. (DOCX $14 \mathrm{~kb}$ )

\section{Abbreviations}

APC: Allophycocyanin; BC: Beckman Coulter; BD: Becton Dickinson; BDB: Becton Dickinson Bioscience; BDH: Becton Dickinson Horizon; BL: Biolegend; BM: Bone marrow; CCR2: C-C chemokine receptor type 2; CCR5: C-C chemokine receptor type 5; CMML: Chronic myelomonocytic leukemia; Cy5.5: Cyanine 5.5; Cy7: Cyanine 7; EPO: Erythropoietin; FAB: French-American-British; FCM: Flow cytometry; FITC: Fluorescein isothiocyanate; FSC: Forward scatter; G-CSF: Granulocyte-colony stimulating factor; GM-CSF: Granulocyte monocyte-colony stimulating factor; Hg: Hemoglobin; HR-MDS: Higher risk myelodysplastic syndrome (IPSS: intermediate-2 + high); IL: Interleukin; IOT: Immunotech; IPSS: International Prognostic Scoring System; IPSS-R: Revised International Prognostic Scoring System; KO: Khrome Orange; LDH: Lactate dehydrogenase; LR-MDS: Lower risk myelodysplastic syndrome (IPSS: low + intermediate-1); mAb: Monoclonal antibody; MCP-1: Monocyte chemotactic protein-1; MCV: Mean corpuscular volume; MDS: Myelodysplastic syndromes; MDS/MPN: Myelodysplastic/ myeloproliferative neoplasms; MDS-del(5q): Myelodysplastic syndromes with isolated deletion of chromosome 5q; MDS-EB: Myelodysplastic syndromes with excess of blasts; MDS-MLD: Myelodysplastic syndromes with multilineage dysplasia; MDS-RS: Myelodysplastic syndromes with ring sideroblasts; MDS-RS-
MLD: Myelodysplastic syndromes with ring sideroblasts with multilineage dysplasia; MDS-RS-SLD: Myelodysplastic syndromes with ring sideroblasts with single lineage dysplasia; MDS-SLD: Myelodysplastic syndromes with single lineage dysplasia; MDS-U: Myelodysplastic syndromes, unclassifiable; MedFl: Median fluorescence intensity; MIP-1alpha: Macrophage inflammatory protein 1alpha chemokine; NA: Not applicable; PB: Peripheral blood; PBS: Phosphate buffered saline; PE: Phycoerythrin; PerCP: Peridinin chlorophyll protein; PerCP-Cy5.5: Peridinin chlorophyll protein Cy5.5; PMT: Photomultiplier tubes; RANTES: Regulated on activation, normal T cell expressed and secreted chemokine; RBC: Red blood cells; SSC: Side-scatter; TNF: Tumor necrosis factor; V450: Violet 450; WBC: White blood cells; WHO: World Health Organization

\section{Acknowledgements}

The authors thank to Marta Gonçalves for cell immunophenotyping, to Ana Sofia Jorge, Cristina Gonçalves, Luciana Pinho, Luciana Xavier, Renata Cabral and Vanessa Mesquita, for patient selection and study implementation, to the other medical doctors and technicians of the Hematology and Pathology Departments for support concerning the routine laboratory tests for MDS diagnosis, and to the nurses for blood collection.

\section{Funding}

The Centro Hospitalar do Porto (CHP) made available the necessary infrastructures and equipment, and the Instituto de Ciências Biomédicas Abel Salazar, Universidade do Porto (ICBAS/UP) gave financial support for the purchase of the reagents used in this study. The funders had no role in study design, data collection and analysis, decision to publish, or preparation of the manuscript.

\section{Availability of data and materials}

The datasets used and/or analyzed during the current study are available from the corresponding author on reasonable request.

\section{Authors' contributions}

AA: study design, data collection, data analysis, and manuscript draft writing. $\mathrm{CL}$ and MAT: flow cytometry data analysis. CM: patient selection, study implementation, and clinical data collection, registry and analysis. AS: transfusion data collection and registry, and analysis; AM: cytogenetic data analysis. IF: cytomorphology. JC: contribution to patient selection and study implementation, discussion of the results, and critical revision of the manuscript; ML: study conception and design, flow cytometry data analysis, clinical and laboratory data review, statistical analysis, and manuscript writing and review. All authors read and approved the final version of the manuscript.

\section{Authors' information}

AA is a medical doctor undertaking general training for medical specialization; she contributed to this work as a medical student, integrated in the curricular unit of initiation to clinical research. CL and MAT are medical doctors specialized in Immunohemotherapy, with skills in flow cytometry; MAT has expertise in MDS immunophenotyping. AS is a medical doctor specialized in Immunohemoterapy, with skills in transfusion medicine. AM is a medical doctor specialized in Clinical Hematology, with expertise in cytogenetics. IF is a medical doctor specialized in Clinical Pathology, with skills in cytomorphology. JC is a medical doctor specialized in Clinical Hematology, head of the Department of Clinical Hematology, with a large experience in diagnosing and treating patients with MDS. ML is a medical doctor specialized in Immunohemotherapy, head of the flow cytometry laboratory, and an expert in flow cytometry applied to the diagnosis of hemato-oncological disorders.

\section{Ethics approval and consent to participate}

The study was approved by the Ethics Committee of Centro Hospitalar do Porto (Luísa Bernardo, medical doctor; Carla Teixeira, medical doctor; Fernanda Manuela, medical doctor; Paulina Aguiar, pharmacist; Paula Duarte, nurse; Maria Manuel Araújo Jorge, philosopher; and Jorge Andrade da Silva, jurist) and Hospital Research Coordination Office, and authorized by the Hospital Administration Board, being registered with the number 2015/123 (110-DEFI/075-CES). All patients and control subjects gave the informed consent prior to entering the study, and the procedures followed were in accordance with the Helsinki Declaration. 


\section{Consent for publication}

Consent for publication was given in the informed consent to participate in the study.

\section{Competing interests}

The authors declare that they have no competing interests.

\section{Publisher's Note}

Springer Nature remains neutral with regard to jurisdictional claims in published maps and institutional affiliations.

\section{Author details}

1Department of Hematology, Hospital de Santo António (HSA), Centro Hospitalar do Porto (CHP), Porto, Portugal. ${ }^{2}$ Department of Pathology, Hospital de Santo António (HSA), Centro Hospitalar do Porto (CHP), Porto, Portugal. ${ }^{3}$ Instituto de Ciências Biomédicas Abel Salazar, Universidade do Porto (ICBAS/UP), Porto, Portugal. ${ }^{4}$ Unidade Multidisciplinar de Investigação Biomédica, Instituto de Ciências Biomédicas Abel Salazar, Universidade do Porto (UMIB/ICBAS/UP), Porto, Portugal. ${ }^{5}$ Laboratório de Citometria, Serviço de Hematologia, Hospital de Santo António, Centro Hospitalar do Porto, instalações do Ex-CICAP, Rua D. Manuel II, s/n, 4099-001 Porto, Portugal.

\section{Received: 4 September 2017 Accepted: 1 March 2018} Published online: 13 March 2018

\section{References}

1. Adès L, Itzykson R, Fenaux P. Myelodysplastic syndromes. Lancet. 2014;383: 2239-52. https://doi.org/10.1016/S0140-6736(13)61901-7. PMID: 24656536

2. Malcovati L, Hellström-Lindberg E, Bowen D, Adès L, Cermak J, Del Cañizo $C$, et al. Diagnosis and treatment of primary myelodysplastic syndromes in adults: recommendations from the European LeukemiaNet. Blood. 2013;122: 2943-64. https://doi.org/10.1 182/blood-2013-03-492884. PMID: 23980065

3. Meers $\mathrm{S}$. The myelodysplastic syndromes: the era of understanding. Eur J Haematol. 2015;94:379-90. https://doi.org/10.1111/ejh.12443. PMID: 25186093

4. Swerdlow S, Camp E, Harris N, Jaffe E, Pileri S. WHO classification of tumors of haematopoietic and lymphoid tissues. Lyon: IARC: 2008.

5. Arber DA, Orazi A, Hasserjian R, Thiele J, Borowitz MJ, Le Beau MM. The 2016 revision to the World Health Organization classification of myeloid neoplasms and acute leukemia. Blood. 2016;127:2391-405. https://doi.org/ 10.1182/blood-2016-03-643544. PMID: 27069254

6. Greenberg P, Cox C, LeBeau MM, Fenaux P, Morel P, Sanz G, et al. International scoring system for evaluating prognosis in myelodysplastic syndromes. Blood. 1997;89:2079-88. PMID: 9058730

7. Greenberg PL, Tuechler H, Schanz J, Sanz G, Garcia-Manero G, Solé F, et al. Revised international prognostic scoring system for myelodysplastic syndromes. Blood. 2012;120:2454-65. https://doi.org/10.1182/blood-2012-03420489. PMID: 22740453

8. Sekeres MA, Schoonen WM, Kantarjian H, List A, Fryzek J, Paquette R, et al. Characteristics of US patients with myelodysplastic syndromes: results of six cross-sectional physician surveys. J Natl Cancer Inst. 2008;100:1542-51. https://doi.org/10.1093/jnci/djn349. PMID: 18957672

9. Stetler-Stevenson M, Arthur DC, Jabbour N, Xie XY, Molldrem J, Barrett AJ, et al. Diagnostic utility of flow cytometric immunophenotyping in myelodysplastic syndrome. Blood. 2001;98:979-87. https://doi.org/10.1182/ blood.V98.4.979. PMID: 11493442

10. Wells DA, Benesch M, Loken MR, Vallejo C, Myerson D, Leisenring WM, et al. Myeloid and monocytic dyspoiesis as determined by flow cytometric scoring in myelodysplastic syndrome correlates with the IPSS and with outcome after hematopoietic stem cell transplantation. Blood. 2003;102: 394-403. https://doi.org/10.1182/blood-2002-09-2768. PMID: 12649150

11. Matarraz S, López A, Barrena S, Fernandez C, Jensen E, Flores J, et al. The immunophenotype of different immature, myeloid and B-cell lineagecommitted CD34+ hematopoietic cells allows discrimination between normal/reactive and myelodysplastic syndrome precursors. Leukemia. 2008; 22:1175-83. https://doi.org/10.1038/leu.2008.49. PMID: 18337765

12. van de Loosdrecht AA, Westers TM, Westra AH, Drager AM, van der Velden VHJ, Ossenkoppele GJ. Identification of distinct prognostic subgroups in low- and intermediate-1-risk myelodysplastic syndromes by flow cytometry. Blood. 2008;111:1067-77. https://doi.org/10.1182/blood-2007-07-098764. PMID: 17971483
13. Westers TM, Ireland R, Kern W, Alhan C, Balleisen JS, Bettelheim P, et al. Standardization of flow cytometry in myelodysplastic syndromes: a report from an international consortium and the European LeukemiaNet working group. Leukemia. 2012;26:1730-41. https://doi.org/10.1038/leu.2012.30. PMID: 22307178

14. Cazzola M. Flow cytometry immunophenotyping for diagnosis of myelodysplastic syndrome. Haematologica. 2009;94:1041-3. https:/doi.org/ 10.3324/haematol.2009.007682. PMID: 19644135

15. Kern W, Haferlach C, Schnittger S, Haferlach T. Clinical utility of multiparameter flow cytometry in the diagnosis of 1013 patients with suspected myelodysplastic syndrome: correlation to cytomorphology, cytogenetics, and clinical data. Cancer. 2010;116:4549-63. https://doi.org/10. 1002/cncr.25353. PMID: 20572043

16. Kern W, Haferlach C, Schnittger S, Alpermann T, Haferlach T. Serial assessment of suspected myelodysplastic syndromes: significance of flow cytometric findings validated by cytomorphology, cytogenetics, and molecular genetics. Haematologica. 2013:98:201-7. https://doi.org/10.3324/ haematol.2012.066787. PMID: 22929975

17. Lacronique-Gazaille C, Chaury M-P, Le Guyader A, Faucher J-L, Bordessoule D, Feuillard J. A simple method for detection of major phenotypic abnormalities in myelodysplastic syndromes: expression of CD56 in CMML. Haematologica. 2007;92:859-60. https://doi.org/10.3324/haematol.11118. PMID: 17550865

18. Selimoglu-Buet D, Wagner-Ballon O, Saada V, Bardet V, Itzykson R, Bencheikh $L$, et al. Characteristic repartition of monocyte subsets as a diagnostic signature of chronic myelomonocytic leukemia. Blood. 2015;125: 3618-26. https://doi.org/10.1182/blood-2015-01-620781. PMID: 25852055

19. Stachurski D, Smith BR, Pozdnyakova O, Andersen M, Xiao Z, Raza A, et al. Flow cytometric analysis of myelomonocytic cells by a pattern recognition approach is sensitive and specific in diagnosing myelodysplastic syndrome and related marrow diseases: emphasis on a global evaluation and recognition of diagnostic pitfalls. Leuk Res. 2008:32:215-24. https://doi.org/ 10.1016/j.leukres.2007.06.012. PMID: 17675229

20. Xu Y, McKenna RW, Karandikar NJ, Pildain AJ, Kroft SH. Flow cytometric analysis of monocytes as a tool for distinguishing chronic myelomonocytic leukemia from reactive monocytosis. Am J Clin Pathol. 2005;124:799-806. https://doi.org/10.1309/HRJ1-XKTD-77J1-UTFM. PMID: 16203279

21. Porwit A, van de Loosdrecht AA, Bettelheim P, Brodersen LE, Burbury $K$, Cremers $E$, et al. Revisiting guidelines for integration of flow cytometry results in the WHO classification of myelodysplastic syndromes-proposal from the international/European LeukemiaNet working Group for Flow Cytometry in MDS. Leukemia. 2014;28:1793-8. https://doi.org/10.1038/leu. 2014.191. PMID: 24919805

22. Valent P, Orazi A, Büsche G, Schmitt-Gräff A, George TI, Sotlar K, et al. Standards and impact of hematopathology in myelodysplastic syndromes (MDS). Oncotarget. 2010;1:483-96. https://doi.org/10.18632/oncotarget. 101104. PMID: 21317447

23. Sandes AF, Kerbauy DM, Matarraz S, Chauffaille Mde L, López A, Orfao A, et al. Combined flow cytometric assessment of CD45, HLA-DR, CD34, and CD117 expression is a useful approach for reliable quantification of blast cells in myelodysplastic syndromes. Cytometry B Clin Cytom. 2013;84:157-66. https:/doi.org/10.1002/cyto.b.21087. PMID: 23475532

24. Alhan C, Westers TM, van der Helm LH, Eeltink C, Huls G, Witte Bl, et al. Absence of aberrant myeloid progenitors by flow cytometry is associated with favorable response to azacitidine in higher risk myelodysplastic syndromes. Cytometry B Clin Cytom. 2014;86:207-15. https://doi.org/10. 1002/cyto.b.21160. PMID: 24474614

25. Eidenschink Brodersen L, Menssen AJ, Wangen JR, Stephenson CF, de Baca $M E$, Zehentner BK, et al. Assessment of erythroid dysplasia by "difference from normal" in routine clinical flow cytometry workup. Cytometry B Clin Cytom. 2015;88:125-35. https://doi.org/10.1002/cyto.b.21199. PMID: 25490867

26. Laranjeira P, Rodrigues R, Carvalheiro T, Constanço C, Vitória H, Matarraz S, et al. Expression of CD44 and CD35 during normal and myelodysplastic erythropoiesis. Leuk Res. 2015;39:361-70. https://doi.org/10.1016/j.leukres. 2014.12.009. PMID: 25582385

27. Cherian S, Moore J, Bantly A, Vergilio J-A, Klein P, Luger S, et al. Flowcytometric analysis of peripheral blood neutrophils: a simple, objective, independent and potentially clinically useful assay to facilitate the diagnosis of myelodysplastic syndromes. Am J Hematol. 2005;79:243-5. https://doi. org/10.1002/ajh.20371. PMID: 15981222 
28. Cherian S, Moore J, Bantly A, Vergilio J-A, Klein P, Luger S, et al. Peripheral blood MDS score: a new flow cytometric tool for the diagnosis of myelodysplastic syndromes. Cytometry B Clin Cytom. 2005;64B:9-17. https:// doi.org/10.1002/cyto.b.20041. PMID: 15668954

29. Sandes AF, Yamamoto M, Matarraz S, Chauffaille M de LLF, Quijano S, López $A$, et al. Altered immunophenotypic features of peripheral blood platelets in myelodysplastic syndromes. Haematologica. 2012;97:895-902. https://doi. org/10.3324/haematol.2011.057158. PMID: 22271903

30. Rashidi HH, Xu X, Wang H-Y, Shafi NQ, Rameshkumar K, Messer K, et al. Utility of peripheral blood flow cytometry in differentiating low grade versus high grade myelodysplastic syndromes (MDS) and in the evaluation of cytopenias. Int J Clin Exp Pathol. 2012;5:224-30. PMID: 22558477

31. Meyerson HJ, Osei E, Schweitzer K, Blidaru G, Edinger A, Balog A. CD177 expression on neutrophils: in search of a clonal assay for myeloid neoplasia by flow cytometry. Am J Clin Pathol. 2013;140:658-69. https://doi.org/10. 1309/AJCPDFBEBQZW1OI7. PMID: 24124144

32. Germing $U$, Hildebrandt $B$, Pfeilstöcker $M$, Nösslinger $T$, Valent $P$, Fonatsch $C$, et al. Refinement of the international prognostic scoring system (IPSS) by including LDH as an additional prognostic variable to improve risk assessment in patients with primary myelodysplastic syndromes (MDS). Leukemia. 2005;19:2223-31. https://doi.org/10.1038/sj.leu.2403963. PMID: 16193087

33. Shenoy N, Vallumsetla N, Rachmilewitz E, Verma A, Ginzburg Y. Impact of iron overload and potential benefit from iron chelation in low-risk myelodysplastic syndrome. Blood. 2014;124:873-81. https://doi.org/10.1182/ blood-2014-03-563221. PMID: 24923296

34. Garcia-Manero G, Shan J, Faderl S, Cortes J, Ravandi F, Borthakur G, et al. A prognostic score for patients with lower risk myelodysplastic syndrome. Leukemia. 2008;22:538-43. https://doi.org/10.1038/sj.leu.2405070. PMID: 18079733

35. Mufti GJ, Bennett JM, Goasguen J, Bain BJ, Baumann I, Brunning R, et al. International working group on morphology of myelodysplastic syndrome. Diagnosis and classification of myelodysplastic syndrome: international working group on morphology of myelodysplastic syndrome (IWGM-MDS) consensus proposals for the definition and enumeration of myeloblasts and ring sideroblasts. Haematologica. 2008;93:1712-7. https://doi.org/10.3324/ haematol.13405. PMID: 18838480

36. Thiele J, Kvasnicka HM, Facchetti F, Franco V, van der Walt J, Orazi A. European consensus on grading bone marrow fibrosis and assessment of cellularity. Haematologica. 2005;90:1128-32. PMID: 16079113

37. Orazi A. Histopathology in the diagnosis and classification of acute myeloid leukemia, myelodysplastic syndromes, and myelodysplastic/ myeloproliferative diseases. Pathobiology. 2007;74:97-114. https://doi.org/10. 1159/000101709. PMID: 17587881

38. Horny H-P, Sotlar K, Valent P. Diagnostic value of histology and immunohistochemistry in myelodysplastic syndromes. Leuk Res. 2007; 31:1609-16. https://doi.org/10.1016/j.leukres.2007.05.010. PMID: 17604834

39. Schanz J, Tüchler H, Solé F, Mallo M, Luño E, Cervera J, et al. New comprehensive cytogenetic scoring system for primary myelodysplastic syndromes (MDS) and oligoblastic acute myeloid leukemia after MDS derived from an international database merge. J Clin Oncol. 2012;30:820-9. https://doi.org/10.1200/JCO.2011.35.6394. PMID: 22331955

40. Kalina T, Flores-Montero J, van der Velden VHJ, Martin-Ayuso M, Böttcher S, Ritgen $\mathrm{M}$, et al. EuroFlow standardization of flow cytometer instrument settings and immunophenotyping protocols. Leukemia. 2012;26:1986-2010. https://doi.org/10.1038/leu.2012.122. PMID: 22948490

41. EuroFlow, a division of ESLHO. https://euroflow.org. Accessed 4 Oct 2017.

42. Kalina T, Flores-Montero J, Lecrevisse Q, Pedreira CE, van der Velden VHJ, Novakova M, et al. Quality assessment program for EuroFlow protocols: summary results of four-year (2010-2013) quality assurance rounds. Cytometry A. 2015;87:145-56. https://doi.org/10.1002/cyto.a.22581. PMID: 25345353

43. Mitchell AJ, Baker-Glenn EA, Park B, Granger L, Symonds P. Can the distress thermometer be improved by additional mood domains? Part II. What is the optimal combination of emotion thermometers? Psychooncology. 2010; 19:134-40. https://doi.org/10.1002/pon.1557. PMID: 19296461

44. Mitchell AJ, Baker-Glenn EA, Granger L, Symonds P. Can the distress thermometer be improved by additional mood domains? Part I. Initial validation of the emotion thermometers tool. Psychooncology. 2010;19: 125-33. https://doi.org/10.1002/pon.1523. PMID: 19296462
45. Ziegler-Heitbrock L. The CD14+ CD16+ blood monocytes: their role in infection and inflammation. J Leukoc Biol. 2007;81:584-92. https://doi.org/ 10.1189/jlb.0806510. PMID: 17135573

46. Ziegler-Heitbrock L, Ancuta P, Crowe S, Dalod M, Grau V, Hart DN, et al. Nomenclature of monocytes and dendritic cells in blood. Blood. 2010;116: e74-80. https://doi.org/10.1182/blood-2010-02-258558. PMID: 20628149

47. Ziegler-Heitbrock L, Hofer TPJ. Toward a refined definition of monocyte subsets. Front Immunol. 2013;4:23. https://doi.org/10.3389/fimmu.2013. 00023. PMID: 23382732

48. Ziegler-Heitbrock L. Blood monocytes and their subsets: established features and open questions. Front Immunol. 2015;6:423. https://doi.org/10.3389/ fimmu.2015.00423. PMID: 26347746

49. Passlick B, Flieger D, Ziegler-Heitbrock HW. Identification and characterization of a novel monocyte subpopulation in human peripheral blood. Blood. 1989;74:2527-34. PMID: 2478233

50. Ziegler-Heitbrock HW, Fingerle G, Ströbel M, Schraut W, Stelter F, Schütt C, et al. The novel subset of CD14+/CD16+ blood monocytes exhibits features of tissue macrophages. Eur J Immunol. 1993;23:2053-8. https://doi.org/10. 1002/eji.1830230902. PMID: 7690321

51. Frankenberger M, Sternsdorf T, Pechumer H, Pforte A, Ziegler-Heitbrock HW. Differential cytokine expression in human blood monocyte subpopulations: a polymerase chain reaction analysis. Blood. 1996;87:373-7. PMID: 8547664

52. Belge K-U, Dayyani F, Horelt A, Siedlar M, Frankenberger M, Frankenberger $B$, et al. The proinflammatory CD14+CD16+DR++ monocytes are a major source of TNF. J Immunol. 2002;168:3536-42. https://doi.org/10.4049/ jimmunol.168.7.3536. PMID: 11907116

53. Weber C, Belge KU, von Hundelshausen P, Draude G, Steppich B, Mack M, et al. Differential chemokine receptor expression and function in human monocyte subpopulations. J Leukoc Biol. 2000;67:699-704. PMID: 10811011

54. Thieblemont N, Weiss L, Sadeghi HM, Estcourt C, Haeffner-Cavaillon N. CD14lowCD16high: a cytokine-producing monocyte subset which expands during human immunodeficiency virus infection. Eur J Immunol. 1995;25: 3418-24. https://doi.org/10.1002/eji.1830251232. PMID: 8566032

55. Blumenstein $M$, Boekstegers $P$, Fraunberger $P$, Andreesen $R$, ZieglerHeitbrock HW, Fingerle-Rowson G. Cytokine production precedes the expansion of CD14+CD16+ monocytes in human sepsis: a case report of a patient with self-induced septicemia. Shock. 1997;8:73-5. PMID: 9249916

56. Koch S, Kucharzik T, Heidemann J, Nusrat A, Luegering A. Investigating the role of proinflammatory CD16+ monocytes in the pathogenesis of inflammatory bowel disease. Clin Exp Immunol. 2010;161:332-41. https:// doi.org/10.1111/j.1365-2249.2010.04177.x. PMID: 20456413

57. Mukherjee R, Kanti Barman P, Kumar Thatoi P, Tripathy R, Kumar Das B, Ravindran B. Non-classical monocytes display inflammatory features: validation in Sepsis and systemic lupus erythematous. Sci Rep. 2015;5:13886. https://doi.org/10.1038/srep13886. PMID: 26358827

58. Saleh MN, Goldman SJ, LoBuglio AF, Beall AC, Sabio H, McCord MC, et al. CD16+ monocytes in patients with cancer: spontaneous elevation and pharmacologic induction by recombinant human macrophage colonystimulating factor. Blood. 1995;85:2910-7. PMID: 7742551

59. Feng AL, Zhu JK, Sun JT, Yang MX, Neckenig MR, Wang XW, et al. CD16+ monocytes in breast cancer patients: expanded by monocyte chemoattractant protein-1 and may be useful for early diagnosis. Clin Exp Immunol. 2011;164:57-65. https://doi.org/10.1111/j.1365-2249.2011.04321.x PMID: 21361908

60. Seidler S, Zimmermann HW, Bartneck M, Trautwein C, Tacke F. Agedependent alterations of monocyte subsets and monocyte-related chemokine pathways in healthy adults. BMC Immunol. 2010;11:30. https:// doi.org/10.1186/1471-2172-11-30. PMID: 20565954

61. Dayyani F, Belge K-U, Frankenberger M, Mack M, Berki T, Ziegler-Heitbrock L. Mechanism of glucocorticoid-induced depletion of human CD14+CD16+ monocytes. J Leukoc Biol. 2003;74:33-9. PMID: 12832440

62. Takuwa N, Kanegasaki S, Asano S, Tomita T, Nakayama E, Sato N, et al. Defective terminal maturation along monocyte-macrophage lineage in chronic myelomonocytic leukemia. Acta Haematol. 1984;72:163-70. PMID: 6438980

63. Soares G, Barral A, Costa JM, Barral-Netto M, Van Weyenbergh J. CD16+ monocytes in human cutaneous leishmaniasis: increased ex vivo levels and correlation with clinical data. J Leukoc Biol. 2006;79:36-9. https://doi.org/10. 1189/jlb.0105040. PMID: 16282534

64. Reis-Alves SC, Traina F, Metze K, Lorand-Metze I. Improving the differential diagnosis between myelodysplastic syndromes and reactive peripheral 
cytopenias by multiparametric flow cytometry: the role of B-cell precursors. Diagn Pathol. 2015;10:44. https://doi.org/10.1186/s13000-015-0259-3. PMID: 25924846

65. Sconocchia G, Keyvanfar K, El Ouriaghli F, Grube M, Rezvani K, Fujiwara H, et al. Phenotype and function of a CD56+ peripheral blood monocyte. Leukemia. 2005;19:69-76. https://doi.org/10.1038/sj.leu.2403550. PMID: 15526027

66. Krasselt M, Baerwald C, Wagner U, Rossol M. CD56+ monocytes have a dysregulated cytokine response to lipopolysaccharide and accumulate in rheumatoid arthritis and immunosenescence. Arthritis Res Ther. 2013;15: R139. https://doi.org/10.1186/ar4321. PMID: 24286519

67. Grip O, Bredberg A, Lindgren S, Henriksson G. Increased subpopulations of CD16(+) and CD56(+) blood monocytes in patients with active Crohn's disease. Inflamm Bowel Dis. 2007;13:566-72. https://doi.org/10.1002/ibd. 20025. PMID: 17260384

68. Xu F, Guo J, Wu L-Y, He Q, Zhang Z, Chang C-K, et al. Diagnostic application and clinical significance of FCM progress scoring system based on immunophenotyping in CD34+ blasts in myelodysplastic syndromes. Cytometry B Clin Cytom. 2013;84:267-78. https://doi.org/10.1002/cyto.b. 21089. PMID: 23554290

Submit your next manuscript to BioMed Central and we will help you at every step:

- We accept pre-submission inquiries

- Our selector tool helps you to find the most relevant journal

- We provide round the clock customer support

- Convenient online submission

- Thorough peer review

- Inclusion in PubMed and all major indexing services

- Maximum visibility for your research

Submit your manuscript at www.biomedcentral.com/submit
Biomed Central 